\title{
VARIATIONS CAUSED IN HEATING CURVES OF GLASS BY HEAT TREATMENT ${ }^{1}$
}

\author{
By A. Q. Tool and C. G. Eichlin
}

ABSTRACT

This paper presents some of the variations that are produced in the heating curves of a glass by subjecting it previously to different heat treatments. The discussion incorporated shows that these variations are often fully indicative of the character of these previous treatments, and also that they bear a relation to the changes caused in numerous other characteristics of glass by the same means.

The differences in the curves presented arise from differences in the thermal properties of the glass, and especially from changes in the magnitude and character of the exothermic and endothermic effects. The physicochemical processes causing the latter effect are the reverse of those producing the exothermic; that is, the two effects are related as in the case of the similar and well-known phenomena observed at an inversion point, such as is found in many crystals. They are, however, not confined to the usual relatively narrow temperature ranges and are also much more subject to undercooling and superheating.

Apparently the resistance to the activity of the physicochemical processes causing these effects in glass increases very rapidly as the temperature is lowered. This makes it possible to suppress the exothermic processes to a great extent by rapid cooling and to prepare the way thereby for relatively large exothermic effects on subsequent heating. Since the preparatory exothermic activity is insuficient, the endothermic effects in the heating curves of chilled glasses are never pronounced, but they may become quite large in these curves after the glasses are annealed in a manner such that the exothermic processes have the opportunity to continue their activity into the range of relatively low annealing temperatures.

During annealing the exothermic activity progresses more and more slowly toward a limit which is determined by the annealing temperature employed, and reducing this temperature advances the limit. The physicochemical condition which the glass would have if the limit for any given annealing temperature were reached is termed "the equilibrium condition" of the glass for that temperature, and such an equilibrium is presumably kinetic in character. The continuous series made up of all these equilibrium conditions corresponding to the various temperatures in the annealing range is called the equilibrium sequence. It is shown that about any portion of such a sequence a glass may be made to follow any number of apparently closed cycles and that in traversing these cycles it passes through a series of intermediate conditions which, in general, do not coincide with the equilibrium sequence except when this is practically insured by very thorough annealing at constant temperatures. At ordinary atmospheric temperatures the usual type of glass is always in such an intermediate series, since in ordinary practice at least it is impossible to extend the realizable equilibrium sequence to temperatures much below the lower limit of the practical annealing range. In this range, however, very low rates of cooling or heating will cause a glass to follow its equilibrium sequence with relative closeness after coincidence has once been practically established.

In view of the present insufficient knowledge concerning the constitution of glass, the particular processes involved in these changes of physicochemical condition are presumably too complex and varied for analysis. Apparently, however, the activity of the exothermic type gives rise to a series of molecular readjustments which in many cases limit the ability of the glass to reach other conditions having possibly greater stability, especially at relatively low temperatures. In some cases these readjustments may insure a greater permanency to the vitreous state so long as the glass is not heated above the temperatures producing them. A relatively clear conception of these readjustments and of the general behavior

${ }_{1}^{1}$ This article includes many of the salient points discussed in a paper, Some Variations Caused in the Physical Properties of Glass by Heat Treatment, read at the meeting of the American Ceramic Society at Atlantic City, N. J., February, 1924. It also contains additional data bearing on those points. 
of glass in the annealing range may be gained from a consideration of the changing conditions in any physicochemical system (for example, a solution) where the equilibrium concition depends upon the temperature, but normally does not change simultaneously with it. From the standpoint of investigating certain properties and characteristics, systems like glass yield advantages since their reaction rates are low and give opportunity for many observations during any change of importance and also since the thermal effects caused by superheating and undercooling are readily detectable.

The relation which the changes in physicochemical condition bear to certain problems in practical annealing is also considered, and from the discussion it will be evident that annealing procedures may often be manipulated so that the resultant changes in certain properties (notably the refractivity) will cause a glass to meet standards of requirement which it would normally fail to reach if annealed according to a fixed schedule prescribed for its general type. Although the tolerances of present-day standards are so lenient that adjustments of this character are seldom required or employed, it is believed that the time is rapidly approaching when an extended use will be made of them, especially in those cases where a highly standardized production of optical instruments of great precision is attempted. More important from the optical instrument standpoint, however, is the need of always annealing a glass in such a way that the physicochemical condition is fully uniform throughout the whole piece or blank from which an optical part is produced. In many cases gradients no greater than a small fraction of a degree will, if they exist during annealing, produce nonuniformities which cause greater disturbances than strains of considerable magnitude.

CONTENTS

I. Introduction

II. Method of obtaining and presenting the heating curves.

III. General characteristics of the heating curves.

IV. Annealing and "disannealing"

V. Detailed exposition of the curves

VI. General discussion and conclusions

\section{INTRODUCTION}

In a previous article ${ }^{2}$ attention was called to the fact that the form of the heating curves obtained on glasses that have been chilled is different from that found on the same glasses after they have been well annealed, and also that this difference in curve form probably indicates the occurrence during annealing of some decided change involving physical and chemical readjustments in the glasses. Through deductions made from data secured by means of an extersive series of heating and cooling curve tests it was concluded that these readjustments, when indueed by annealing, usually effect a shift of the physicochemical equilibrium of a glass to those conditions which are normal at lower tempcratures, although it was found that displacements in the opposite sense can easily be accomplished by appropriate heat treatments. It was also noted that the equilibrium reached depended on the annealing temperature, and, as a consequence, it appeared that any temperature gradients that may exist during annealing will produce corresponding local variations in the physicochemical condition, and thereby cause the glass to be inhomogeneous. Ifor this reason, as well as for the avoidance of strain, temperature gradicnts should be climinated, in so far as practicable, when a glass intended for certain types of high precision instruments is being rnmealed.

For some of these instruments it is evident that gluss besides possessing high degrees of structural homogeneity should also be in a physi-

IJ. Op. Soc. Am., 4 p 3.10; 1920. 
cochemical condition of considerable stability. This stability is increased when the temperature corresponding to the equilibrim is lowered; consequently, adequate annening at temperatures somewhat lower than those usually employed is, at times, necessary. In the article mentioned it was pointed out, however, that in general it is unnecessary, if not practically impossible, to reduce the usual types of glass to conditions of equilibrium corresponding to those temperatures at which glass is ordinarily employed. This certainly holds for most glasses in common use because the rates at which the changes in equilibrium take place always become very low even at moderately low annealing temperatures; while at temperatures approaching those of ordinary service, these rates are almost always negligible even if the glass is rather poorly annealed.

Additional evidence is given in the present paper sbowing that from a practical standpoint it is not only irnpossible to reduce a giass of the usual type to any of the conditions which would constitute a vitreous equilibrium in the temperature range of ordinary service but that it is also difficult while cooling such a glass to inaintain conditions which correspond ${ }^{3}$ fully to any of the equilibrium conditions which may be easily reached at temperatures in the upper part of the annealing range. In other words, a piece of glass used at any temperature in the range below those temperatures at which it will deform at a perceptible rate under moderate stresses is seldom, if ever, in a condition of physicochemical equilibrium at the service temperature, since its actual condition even when it is used at temperatures relatively near this deformation range usually corresponds more closely, although never exactly, to an equilibrium that may be reached only by sufficiently long heat treatment at some other temperature which in some special cases may be lower, but which is ordinarily much higher than the service temperatures. The use of the glass, so long as the actual physicochemical condicion is practically permanent and uniform throughout the whole piece, may, however, be continued indefinitely without detrimental effects arising from such difierences between the actual and the equilibrium temperatures.

In a glass of homogeneous chemical composition the physicochemical condition, or constitution, and the lack of uniformity in this condition in any given specimen, or between different specimens from the same melt, are determined chiefiy by the treatments to which the glass was subjected in the molding and annealing temperature ranges. Neither the physicochemical constitution nor its possible lack of uniformity, however, is materially aflected by the magnitude of moderate elastic strains present at any time, although both are subject to changes whenever the glass is being annealed and although, in being changed, they affect both the distribution and the apparent relaxation rates of the strains. When these changes in the constitution of a glass are produced by means of a suitable annealing, the properties can, in certain cases, be made more desirable, especially since the resultant increase in uniformity often reduces much of the variation in properties sometimes found even within a single small piece of glass. It was consequently suggested in the article cited that annealing a

Whenever it is said that the physicochemical condition at the actual temperature of the glass corresponds to another condition in which it may he found to exist at sorne other temperature, the word "correspond," is used here, is intended to convey the idea that the two conditions are the sime in every respect except that the material has undergone ibose normal changes in density, heat content, etc., which accompany every such change in temperature, but which do not involve chemical reactions and changes in state or degrees of solution and aggregation. 
glass intended for optical or other precision instruments involves much more, in general, than the removal of the stresses which cause the birefringence commonly used to indicate the quality of annealing.

In a later paper ${ }^{4}$ in which the effects produced on the form of the heating curves obtained after treating a glass at different temperatures, but for equal periods of time, were fully discussed, it was stated that a gradual increase in the treating time at any given temperature produces a progressive change in this curve form until a physicochemical equilibrium for that particular treating temperature has been reached by the glass. It was also pointed out that the form of the curves, when obtained on samples in such equilibria, changes as the treating temperatures corresponding to the equilibria are varied; and that these variations in the treating procedure which are caused by varying either or both the temperature and period of treatment produce changes in certain physical properties of the glass that can be coordinated to a certain degree with the observed changes in form of the heating curves.

Since it was also found from these effects that the condition approached at any given treating temperature always appears to be practically the same regardless of whether the glass was originally in equilibrium at a higher or a lower temperature, it was concluded after testing many glasses that in most cases long and continuous series of equilibrium conditions which change with the temperature can be definitely established. (A section of such a series and certain possible cyclic changes about it are represented in fig. 2.) It was also concluded that by holding a glass successively, for a sufficient time, in every small temperature interval within the corresponding wide temperature range it may, when either heated or cooled, be made to follow its particular series of equilibrium conditions throughout this extensive temperature range. Such a range is often much wider than, and usually contains the whole of, the practical annealing range of a glass. Although the temperature limits between which this series of equilibrium conditions can be established in practice have not been definitely determined for any glass, it seems certain from the results so far obtained that in many cases such ranges extend from temperatures well above, to temperatures considerably below the commonly accepted limits of the seemingly anomalous effects observed in the expansion and the heating curves of the corresponding glasses.

Although some of the more interesting data and a few of the more illustrative curves have from time to time been published it has naturally been impossible to present more than a small portion of the results on which the above conclusions were based. In this paper, therefore, some additional data and a further discussion of the general subject are given. It is believed that all these new data are in full accord with the above conclusions and confirm, in part, some of the opinions advanced by other investigators, notably Marchis. ${ }^{5}$ The chief object of this paper is, however, to show some of the changes appearing in the heating curves obtained on samples taken from time to time from a glass while it is, by continued treatment, being gradually advanced toward equilibrium at a given treating temperature from a condition of practical equilibrium corresponding to some other temperature.

IJ. Opt. Sol. Am. and Rev. Sci. Int., 8, p. 419; 1924.

'I. Marchis, Les Modifications Permanentes du Verre et le Deplacement du Zero des Thermometres;
Parls, ises. 


\section{METHODS OF OBTAINING AND PRESENTING THE HEATING CURVES}

As the methods and apparatus employed in obtaining these heating curves by the use of a differential thermocouple have been fully described in the articles already cited, ${ }^{6}$ a complete discussion of them will be omitted here. It suffices to say that with the modified apparatus now used, the temperatures of both the glass and the neutral body, and the difference between these temperatures can be easily determined by separate measurements. The following more detailed information concerning the measurements and the resulting graphs is, however, necessary for a satisfactory interpretation of the data presented.

In curve 14 (fig. 3), for example, the difference between the ordinates for any two points on the curve represents the change observed in the temperature difference between a $1.5 \mathrm{~g}$ sample of granular glass ${ }^{7}$ and a neutral body ${ }^{8}$ having a volume about equal to that of the glass as both, packed in close contact, are heated at a steady rate of approximately $6^{\circ} \mathrm{C}$. per minute ${ }^{9}$ through the temperature range limited by the temperatures indicated by the abscissas of the two points being considered. Thus the abscissas represent the temperatures of the glass as it is being heated while the ordinates if their zero is established show the corresponding differences between the temperatures of the glass and neutral body.

It is, however, unnecessary to establish this zero in most cases, since under the conditions usually encountered in experiments of this sort the actual temperature of the glass body even in ranges free from abnormal heat effects may be either higher or lower than that of the neutral body because the direction of the heat flow in the furnace can never be fully controlled. By the use of a good thermocouple that has been properly placed in carefully packed bodies, this difference in temperature between the bodies can, however, be kept small in most cases, and it then shows no great variation from test to test on samples of the same glass. When this difference is small it appears that it is caused chiefly by the differences between the heat capacities and conductivities of the glass and neutral bodies-a view which is strengthened by the appearance of an appropriate change in the temperature difference whenever another glass with a different thermal capacity is tested under the same conditions.

Furthermore, in an investigation of this kind it is impossible to eliminate all the troublesome effects encountered in the use of differen-

\footnotetext{
${ }^{6}$ In addition to the articles mentioned, see B. S. Sci. Paper No. 358 (1920), entitled "Concerning the Annealing and Characteristics of Glass."

7 Granules of glass having an average equivalent diameter of about $1 \mathrm{~mm}$ were used because the needed immersion and contact for the thermocouple were thus obtained with less difficulty than is encountered by using solid samples and with none of the peculiar effects found upon employing finely powdered glass. 8 The neutral bodies used in these experiments were composed of fine granular alundum, although other materials have at times been employed and have usually been found suitable if they are free from disturbing heat effects in the required temperature ranges.

This rate of heating has been found to give good results in determining the relative magnitudes of both the exothermic and the endothermic effects obtained with different samples. With all other conditions of the tests kept practically the same, it is possible by maintaining the heating rate reasonably constant throughout a series of tests, to compare the curves obtained for the various samples tested and to have a reasonable assurance that any differences in curve form noted are the result of differences in the previous heat treatments or in the character of the glasses. As shown in a previous paper (see footnote 4, p. 526) this method of comparison also makes it possible to determine the period of treatment required at a given treating temperature either to bring a glass into approximate equilibrium there or to cause it to show the heat effects corresponding to any of certain intermediate conditions through which the glass must pass in approaching equilibrium at this temperature and which may or may not be practically identical with approximate equilibrium conditions for certain other temperatures.
} 
tial thermocouples, especially when a long series of tests is being made. If the couple has been used for some time and the wires have become contaminated or otherwise changed in character, the two parts of the differential thermocouple may become dissimilar and cause the introduction of possible errors which, although relatively insignificant in actual temperature determinations of these tests, become troublesome when they enter into the observed temperature differences whose magnitudes are never more than a few degrees. Such crrors in these differences may reach a degree or more, although if care is taken they seldom become so large. Moreover, they never vary disturbingly in the temperature range covered by these particular tests during the time required for obtaining the data for limited series of curves; consequently the variability of the error in the differences between the ordinates of any comparable pairs of points on difierent curves is relatively small.

Since these ordinate differences are comparatively free from error and are at the same time fully indicative of the change in curve form when two curves are compared, it is possible for the purpose of this paper to ignore in most cases the actual magnitudes of the ordinates themselvos which represent the differences in temperature between the neutral and glass bodies. Preferably, therefore, in considering a series of these heating curves they should all be made to coincide at a point corresponding to some temperature (see fig. 4) where it is probable that the glass has in every case reached practically the same physicochemical conditions; or, if this method of presentation causes confusion through the intermingling of a large number of curves, the curves may be presented one above another in some desirable order. (See fig. 3.) In the latter case, if critical intercurve comparisons seem desirable, reference points may be taken at some chosen and identical temperature on all of the curves. To determine the necessary ordinates at the temperatures where the comparisons are to be made, these ordinates should in every case be determined in relation to the reference point on the curve to which they belong. These relative ordinates for any curve may then be compared with those similarly determined for any other curve in its series.

\section{GENERAL CHARACTERISTICS OF THE HEATING CURVES}

The typical appearance of a heating curve for chilled glass (curve 27, fig. 7) is radically different from that for one which has been annealed (curve 38, fig, 9). Curve 27 shows the presence of an cxothernic effect between $350^{\circ}$ and $550^{\circ} \mathrm{C}$., since in this range the curve rises rapidly from its initial level to a maximum and then, at somewhat higher temperatures, goes into a steep decline to a lower level. This decline indicates either or both of two effects: an endothermic effect, or a relatively rapid change in the specific heat and conductivity of the glass. Curve 38 shows no exothermic effect but the decline to a minimum is so marked that the presence of an endothermic effect is definitely established. Granting the presence of these effects, it appears that both the exothermic and endothermic effects must be nssociuted with certain changes in the constitution of the glass, and 
that these constitutional changes are to a great extent responsiole for any change in the thermal properties that is indicated by the form of the curves. On these assumptions, a hypothesis concerning both the behavior of glass when heat-treated and the characteristics of the heating curves presented in this paper will be developed.

The exothernic effect occurs when a chilled glass is heated because this glass while being heated through the lower part of the temperature range of this effect is, from a physicochemical standpoint, in a series of very unstable conditions which correspond more nearly to the equilibria which are attainable at temperatures above the point where the curve maximum occurs than they do to those equilibrium conditions which the glass is approaching so long as it is in the temperature range below the point of this curve maximum.

In the consideration of these unstable conditions it is desirable to select some characteristic of a glass in a given condition that will difierentiate that condition more or less definitely from all other conditions in which the glass may exist at the same actual temperature. A theoretical temperature corresponding to that equilibrium condition which most closely resembles the given condition is suitable for this purpose, since the glass assumes these unstable conditions because the chilling treatment produced an under cooling, the exceptional magnitude of which may be visualized in this way; that is, this equilibrium temperature in falling during the chilling treatment (see curves $A^{\prime}$ and $B^{\prime}$, fig. $1(b)$ lagoed farther and farther behind the acutal temperature of the glass as the cooling progressed and became practically stationary much sooner (relatively speaking) than the latter and at a point which was well above the usual annealing range where equilibrium conditions are normally approximated as a result of ordinary annealing treatments.

On reheating the glass from room temperature, to procure a heating curve for example, this instability first becomes evident when the rise in actual temperature has proceeded far enough to allow (in view of the increased mobility of the glass and of the time lapse per degree increase in temperature) an appreciable activity of those exothermic processes in the glass which were suppressed by the chilling and which, under the favorable conditions of a sufficiently slow cooling and until too greatly hampered by the increasing rigidity of the glass and other unfavorable conditions, would ultinately have caused the equilibrium temperature to fall much farther and would have assisted correspondingly in the establishment of definite physicochemical equilibria in this temperature range of temporary instability. Owing to the increasing activity of these processes as the temperature rises, the constitution of the glass changes for a time more and more rapidly, and as a result the exothermic effect increases for a time. This continues until the changing condition of the glass approaches so closely to the equilibrium condition corresponding to the actual transiont temperature attained that the process activity reaches its maximum while the exothermic effect and heating curve pass through their maxima. Beyond this point further heating soon causes the rising temperature of the glass to reach, pass, and, so long as its rise continues, to remain in advance of the more slowly changing equilibrium temperature which after the coincidence is also rising. 
In other words, during the chilling treatment of the samples employed in this investigation this hypothetical equilibrium temperature was, in view of the undercooling, falling more slowly than the actual temperature of the glass (see fig. $1(b)$ ) and, when the glass was reheated

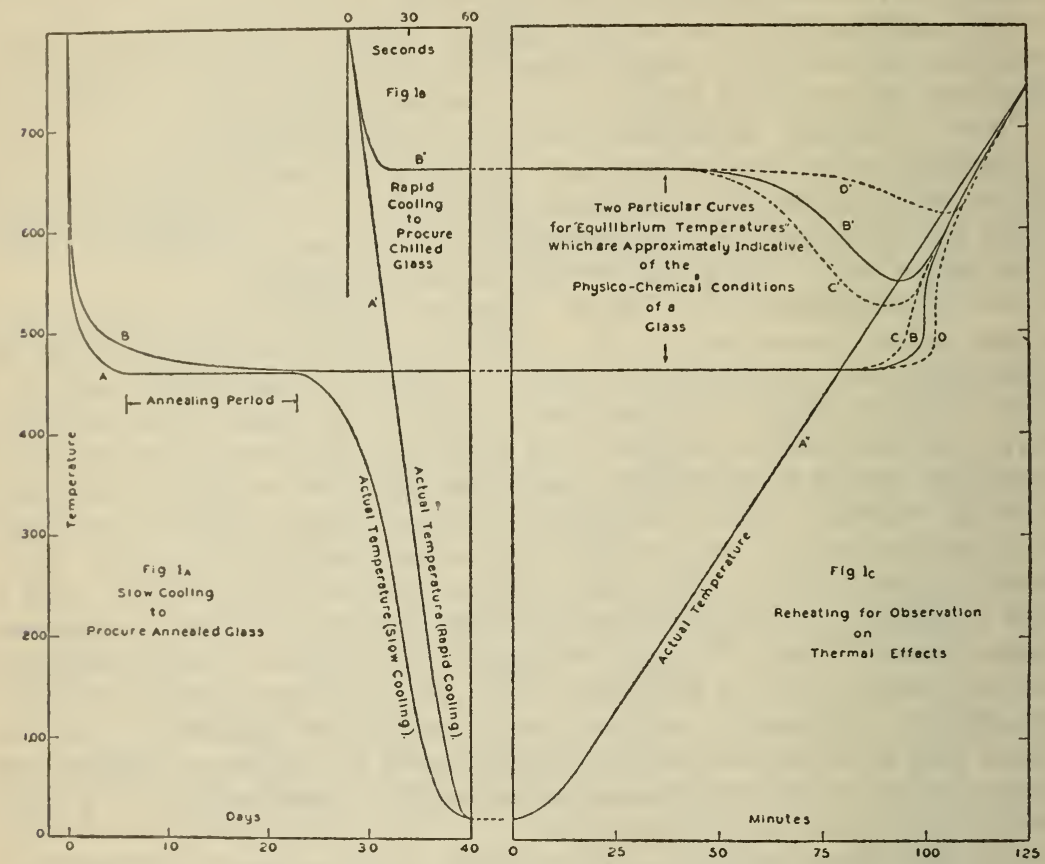

FIGURE 1.-An approximate representation of the courses of the actual and equilibrium temperatures during the processes of annealing, chilling, and testing glass samples

In part $\mathrm{A}$ of this figure, curve $A$ is intended to represent roughly the course of the temperature of a sample of glass at all times during a relatively thorough annealing schedule in which the annealing temperature is chosen quite low in the practical annealing range. Curve $B$ represents the course of the temperatures at which the glass would be found to be in equilibrium at various times; that is, if the temperature of the glass were at any time during the annealing raised quickly from curve $A$ to $B$ no further changes of a marked degree would be noted in the refractivity, density, etc., so long as the temperatureremained constant.

Curves $A^{\prime}$ and $B^{\prime}$ in part $B$ have a corresponding significance in a case where a glass sample is supposed to cool very rapidly

In part $C$, curve $\Lambda^{\prime \prime}$ represents the course of the temperature of either of these samples if they are heated at a normal rate for heating curve tests. Curves $B$ and $B^{\prime}$ sinow the corresponding changes in the equilibrium temperatures of the two samples. Curves $C$ and $C^{\prime}$ would represent the respective corresponding changes if the lieating rate had been lower; while $D$ and $D^{\prime}$ represent the same for an increased rate. For both the slower and faster rates it is evident that (as the curves are plotted) the abscissas must be multiplierl by appropriate factors. It will also be evident that the magnitude and definiteness of the exothermic effects observed in the heating curves obtained on the chilled glass (curve 2, fig. 3 is an example) will depend primarily on the extent to which $B^{\prime}, C^{\prime}$, and $D^{\prime}$ drop below the original level of $B$, the quantity of hent thereby liberated, and the heat capacity of the test sample, although the samples' insulation is also a factor. The magnitude and definiteness of the endothermic effects in the heating curves of both the chilled ancl annealed samples (curves 2 and 14, fig. 3 ) will be controlled mainly by the lags of curves $B^{\prime}$, $C^{\prime}, I I^{\prime}, I 3, C^{\prime}$, and $D$, below the curve $A^{\prime \prime}$ after crossing it. They will also be affected by the rapidity with whlch these curves regain their losses at ligher temperatures and the quantity of heat absorbed per degree rise in the eruilibrium temperature. The lieat capacity and insulation of the samples as in the case of the exothermic effocts are additional factors.

for testing, it resumed falling at an appreciable rate as soon as temperatures were reached that made the instability of the glass apparent. (Curve $B^{\prime}$, fig. $1(c)$.) $\Lambda$ s the actual temperature of the glass continued to rise (curve $\Lambda^{\prime \prime}$, fig. $1(c)$ ) this decrease in the equilibrium temperature continued until the two temperatures momentarily 
coincided. ${ }^{10}$ Presumably this occurred before the curves in Figure 4, for example, fell noticeably below the first level. After this coincidence of the two temperatures at the crossing of curve $A^{\prime \prime}$ by $B^{\prime}$ it is assumed that the actual temperature again led as it did during the chilling treatment, and that the glass at the moment of coincidence was changed from the undercooled to the superheated state; that is, if the actual temperature of a glass can be made to fall more rapidly than the equilibrium temperature and thereby cause undercooling it should also be possible to make it rise faster and cause superheating if all, or even a part, of the physicochemical processes involved in the undercooling of the glass are of a type which favor such a reversal.

This reversal and the attendant superheating, which are indicated in Figure $1(c)$ by the lag of the equilibrium temperature below the actual temperature of the glass after the coincidence, rapidly build up the condition for an endothermic effect which will occur as soon as a temperature range is reached where the mobility of the glass is such that the superheating can no longer be maintained without an excessive increase in the heating rate. The superheating then disappears so rapidly (as the equilibrium temperature gains on the actual) that an abnormal heat absorption becomes evident over a narrow temperature range. That is, whenever, in view of the quantity of heat required by the endothermic processes involved in its disappearance, this superheating and its rate of disappearance are large enough the resulting abnormal heat absorption will cause a steep decline of the heating curves shown in the last nine figures to a more or less well-defined minimum before the second or final level portion of the curve is attained in a temperature range which is usually located just below that of sintering. To a great extent these processes responsible for the endothermic effect are undoubtedly the reverse ${ }^{11}$ of those that were previously moving the condition of the glass from approximate

10 A lower heating rate than that chosen for the heating-curve test would have allowed the exothermic processes in the chilled sample to proceed further toward the equilibria of lower temperatures. (Curve $C^{\prime}$, fig. $1(c)$.) Such a test condition should increase the exothermic effect in a heating curve similar to No. 27 and might have increased the subsequent endothermic effect somewhat, although a low heating rate is unfavorable both to the building up of corresponding temperature differencesiand to superheating. If the heating rate is too low, an exothermic effect will not be found, since the heat liberated will be dissipated without a detectable rise in temperature and, for the saine reason, an endothermic effect may not be observed; that is, the heating curve will drift gradually from the first into the second level. On the other hand, if the heating rate could be made great enough it should be possible as indicated by curve $D^{\prime}$ (fig. $1(c)$ ), to suppress almost completely the exothermic effect shown by heating curve and to delay the endothermic effect (in a glass similar to melt 431 , for instance) until temperatures higher than those of the maxima for this effect (see curves 27 and 28) are reached. In reality heating at a rate equal to or greater than that of the cooling previously employed in chilling a glass should practically eliminate all trace of an exothermic effect and possibly most of the endothermic effect in the curves because that would allow so little time for those changes in condition which are necessary for these effects. With annealed glass, however, increasing the heating rate (see curve $D$, fig. $1(c)$ ) should always increase the observable endothermic effect. It should also increase the temperature for the maximum of this effect but because of the rapid rate at which glass softens at high temperatures such a shift will never be large. Slight shifts which are not entirely traceable to errors in temperature measurements have, however, been observed. Decreasing this rate in the heating curve test of annealed glasses (curve $C$, fig. $1(c)$ ) should decrease the endothermic effect and lower the temperature for its maximum somewhat.

11 It is to be assumed, of course, that all the processes do not reverse at the same time and temperature and also that the reversal temperature of a given process is not at all times the same, since, in general, such a temperature will often depend not only on the process but also on the general condition of the glass and the degree to which the process had advanced. Some processes may first become active in a cooling glass when it has cooled to a certain temperature and, although they may continue active at still lower temperatures so long as they are not completed, the ultimate degree of completion may never exceed that which might have been attained at the starting temperature. The reversal temperatures of such processes will generally be as high as those of starting. Examples of such reversible processes would be the retarded crystallization and the liquefication of relatively insoluble components. With other processes the attainable degree of completion may increase continuously as the temperature of the glass falls (or rises), and in such cases the reversal temperatures of the processes will generally be lower on cooling and higher on heating than the starting points, and will be determined mainly by the advance the corresponding processes have made. This latter type of process is considered to be the chief cause of the heat effects observed. It is, of course, evident that at all temperatures there may be simultaneously active both exothermic and endothermic processes, especially when an unannealed glass is being heated. The observed heat effects are due, therefore, to a preponderance in either number of effectiveness of the one or the other type. 
equilibrium at high temperatures toward those conditions which correspond more or less closely to equilibria at lower temperatures. Actually the vanishing exothermic effect probably overlaps the endothermic efiect to a considerable extent if several types of processes are involved.

Since the temperature range of the endothermic effect as shown by the heating curves is much higher than that of the exothermic effect, it follows that the mobility of the giass is increasing at a much greater rate in the temperature range of the former. Consequently it is to be presumed that the endothermic processes have at these higher temperatures a much greater rate of increase in their activity than the exothermic processes have at the lower temperatures. This assumption gives an explanation for the relatively narrow temperature range of the endothermic effect as compared with that of the exothermic.

It will be noted that the minima for curves 27 and 88 both occur near $600^{\circ} \mathrm{C}$., but that the one for the chilled glass is not so well defined as that for the annealed. The relative indefiniteness of the chilied-olass minimum (curve 27 ) is generally observed in all chilled glasses and is to be ascribed to a reversal of a majority of the exothermic processes before they were completed to the extent required to produce even an approximate equilibrium at any temperature below that where the endothermic effect begins. (This is about $550^{\circ} \mathrm{C}$. for the glass used in obtaining the curves now being considered.) That is, the reversals were brought about in reheating this chilled glass before the exothermic processes had time to produce the conditions necessary for a marked superheating. In fact, it is possible that some of the more important of these processes are so sluggish in their activity during the reheating that they had not reached a condition requiring their reversal until the actual temperature of the glass had reached or exceeded $600^{\circ} \mathrm{C}$. Throughout the range of the endothermic effect in the curves for the chilled glasses such unreversed processes were therefore exothermically active and were reducing the observed endothermic effects caused in the curves by the more advanced process which were reversed at lower temperatures.

In the case of the annealed samples of this glass, bowever (see curve 38), the previous annealing treatment gave all exothermic processes the opportunity to proceed much further toward establishing equilibria corresponding to temperatures below $500^{\circ} \mathrm{C}$. Consequently, when these samples were reheated both the number of process reversals from neutral and exothermic to endothermic action at temperatures below $550^{\circ} \mathrm{C}$. and the total effect of the resultant endothermic processes as the superheating began to diminish rapidly near this temperature were greatly increased, while the number of nxothermic processes and their effect at temperatures near $600^{\circ} \mathrm{C}$. were correspondingly reduced. Since it is here assumed that in any class being heated the number of reversals is always larger in annealed than in chilled samples at those temperatures in a range just below a limit which corresponds in this particular glass to $550^{\circ} \mathrm{C}$., and also that this increaso is always gained from the relatively sluggish processes, it follows that on reheating the annealed samples to obtain heating curves a much greater superheating and a correspondingly larger endothermic effect with its maximum at slightly higher temper- 
atures should always be expected as the thoroughness of annealing increases.

To a great extent an above-mentioned difference which exists between the first and second levels of these heating curves is doubtlessiy attributable to changes in the specific heat and the thermal. conductivity of the glass as its temperature and physicochemical condition are changed by heating from the lower to the higher corresponding temperature ranges. The specific heat, for example, may be changed rapidiy and appreciably as the temperature changes if the exothermic and endothermic effects occurring between these ranges are associated with processes which so change the physical and chemical associations and arrangements of the molecules and ions chat the types, numbers, degrees of freedom, etc., of these units, are rapidly decreased or increased. On this basis, it would appear that the second level, since it is in the higher temperature range where the specific heat is normally greater, should lie below the first as it actually does. Also it would seem that a chilled glass should have a higher specific heat in the temperature range of the lower level than an annealed glass. Acting alone this difference in specific heat, if it

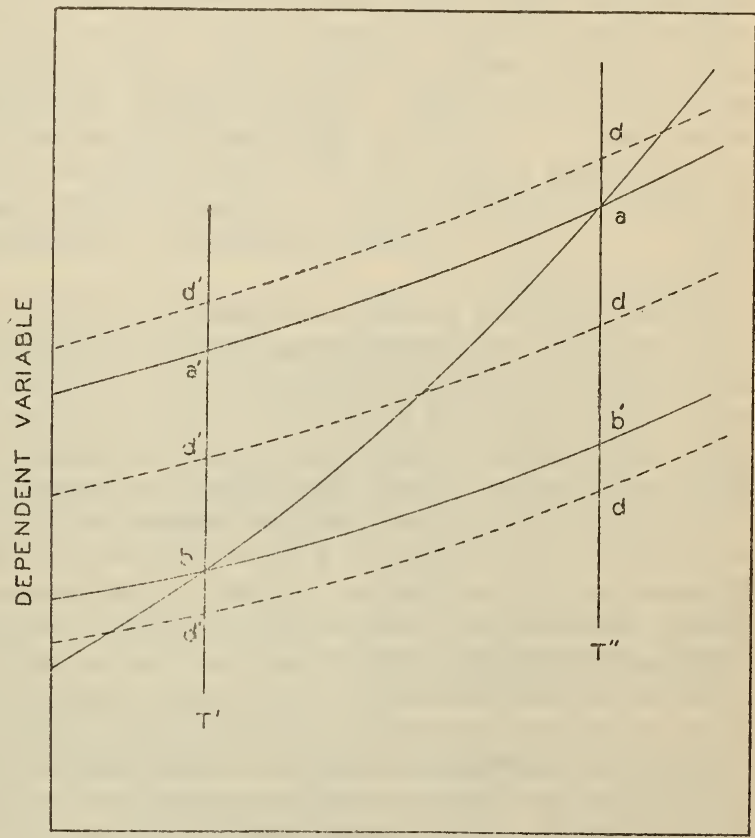

TEMPERATURE

FIGURJ 2.-A representation of the cyclic changes in the physicochemical condition of a vitreous material. (See discussion in footnote $12, p .554$ )

With the possible exception of equilibrium curves, such as $a b$, lines drawn in a plane and representing the various possible sequences of conditions must be considered as mere projections of curves in a multidimensional spaco since, even with the prassure constant, one dependent variable determined on a single property of the material is presumably insufficient to determine the course of such changes in condition unless the equilibium sequence is being followed. For that reason, as indicated in the footnote, the lines $d d^{\prime}$ in particular must be considered as projections of curves which, in general, do not cut the line ab. exists, should make the difference between the first and second levels greater for the annealed glasses than for the chilled. Actually, however, this condition is seldom observed, since these differences between the levels are (for a given glass) usually found to be almost equal for all samples regardless of their previous heat treatment except that in those cases where the samples have been very severely chilled they, contrary to the above deduction, yield differences which are relatively quite large. (See curves 2, fig. 4, and 27 and 31, fig. 8.) These results make it appear that in obtaining a heating curve the effect of the increased specific heat of a chilled glass is 
generally balanced and, in the case of severely chilled glasses, completely outweighed by the effect of an equally possible increase in the thermal conductivity. This would seem to indicate that the thermal diffusivities of such chilled glasses at atmospheric temperatures are relatively large. This comparatively large difference between the initial and final levels of a curve on severely chilled glass may, however, also be caused by some of the exothermic processes becoming active before the first observations are taken; that is, soon after the glass reaches $100^{\circ} \mathrm{C}$. While this, for various reasons, seems relatively improbable as an explanation for all of the increase in the difference, it is evident that any heat released by such processes as might be active in this range would reduce the apparent specific heat by raising the curve level. At this point, it must also be noted that below $300^{\circ} \mathrm{C}$. no really significant departure from the initial level by the curves referred to was observed; and while this may be considered as indicating that no exothermic processes were active in that range, it is also an obvious cause for overlooking such an activity if it were present.

In well-annealed glasses, on the other hand, it may be safely assumed that processes of this sort are so nearly completed or are so thoroughly inactive in this range of relatively low temperatures that the initial level of the curves is determined almost entirely by the real specific heats and thermal conductivities of the samples. At and near the final level, however, both the chilled and annealed glasses are assumed to be approaching the equilibria corresponding to each passing temperature so rapidly that very little difference is to be expected between their respective conditions. Their curve levels should consequently almost coincide in this range of higher temperatures. Until the sintering range is almost reached the curves on chilled samples should, however, be slightly higher since some vestige of activity on the part of the exothermic processes probably still exists while the activity of endothermic processes which are predominant at these temperatures has as yet not become quite so great as in the annealed samples. As in the range of the initial level for chilled glasses the activity of the processes again affects the apparent thermal capacity and conductivity; but since the predominant activity, especially in annealed glass, is now endothermic, the effect it has must be either an apparent increase in the specific heat or an apparent reduction in thermal conductivity which is the opposite of the effect of the exothermic activity at the initial level. As a result of the influence of these exothermic and endothermic effects the differences between these two levels probably always indicate a greater change in these two properties than that which actually occurs; that is, between these two temperature ranges the change in specific heat, for example, is henerally greater than the corresponding change in the "true specific

1" The terms "truo" and "apparent" specific heats are used here merely for the purpose of making clear a distinction which exists between a specific heat that is not, and one that is, increased or decreased by endothermic or exothermic offects which are anomalous in the nature of this coeficiont and whose presence, since they are often small and may not be confined to definite and narrow temperature ranges, is in many cases unsuspecterl. Such a clarification seemed desirable from the standpoint of promoting a better underst anding of the variable results which are possible in all measurements on the different thermal coeflicients of the various materials possessing indefnite effects of this sort. If these offects are caused by certain internal jiroresses which in establisling equilibria consume considerable periods of time in reaching the required ture and the peneral which, together with the velocities of the processes, are determined by the temperacuomcients can be verydion of the material, it follows that their relations to such variations in these coeflcients can be very simply illustrated since the conceptions and facts involved are practically those 


\section{ANNEALING AND "DISANNEALING"}

In its application to the progressive change in form of the heating curves as the heat treatment of the glass is altered to increase the thoroughness of the annealing, the foregoing discussion, together with the conceptions it involves probably requires some elaboration which, to some extent, will be found in the following recapitulation:

1. As the temperature of a glass in the annealing range is reduced very slowly its physicochemical equilibrium changes correspondingly because of the activity of a number of slow exothermic processes which, in the case of a more rapid cooling, are suppressed and which after being suppressed will again resume activity, causing a detectable and an apparently abnormal exothermic effect, whenever the glass is reheated at a rate which is lower than that of cooling.

2. The indication of an exothermic effect usually observed on cooling curves of glass is caused by the cessation of the activity of these exothermic processes as undercooling begins.

discussed in the usual textbook presentation of The Influence of Temperature Upon the Heat of Reaction (See Nernst's Theoretical Chemistry, p. 599, English translation of the 6th ed., 1911.)

For instance, consider a sample of glass, having a mass of $1 \mathrm{~g}$. and a length of $1 \mathrm{~cm}$., which is in physicochemical equilibrium at the temperature, $T^{\prime \prime}$, where, although the changes are assumed to occur not too rapidly, such a condition can be reached in a reasonable time; that is $T^{\prime \prime}$ is chosen in the usual annealing range. If the glass is cooled at a sufficiently rapid rate from this temperature through an interval, $T^{\prime \prime}-T^{\prime}$, there will be a contraction, $C^{\prime \prime}$, and a heat emission, $S^{\prime \prime}$, while the glass passes through that normal series of conditions, $a a^{\prime}$ in fig. 2, which in this interval "corresponds" to the equilibrium condition at $T^{\prime \prime}$. (See footnote 3 , p. 525.) Under these circumstances $S^{\prime \prime}$ and $C^{\prime \prime}$ are changes caused entirely by processes which follow instantaneously any temperature change. If the glass is now held at $T^{\prime}$ until physicochemical equilib. rium is established at that temperature there will occur a further contraction, $c^{\prime}$, and heat emission, $s^{\prime}$. The particular values of the contractions and heats of reaction which may occur at $T^{\prime}$ are those, therefore, which accompany the specific change, $a^{\prime} b$, from a condition corresponding at that temperature to the equilibrium, at $T^{\prime \prime}$ to equilibrium at $T^{\prime}$.

If, however, the glass is cooled so slowly-in the upper part of the annealing range such a cooling may be made quite rapid but in the lower part it must be extremely slow-that it passes only through the series $a b$, of equilibrium conditions, the contraction and heat emission, $C$ and $S$, respectively, will be observed for the interval, $T^{\prime \prime}-T^{\prime}$; and in this case $C$ and $S$ are caused not only by the instantaneously responsive processes, but also by those which require time and which were responsible for $c^{\prime}$ and $s^{\prime}$. Since the equilibrium conditions at $T^{\prime \prime}$ and also at $T^{\prime}$ are presumably the same for both cooling methods (except in certain causes not considered here) it follows that $C=C^{\prime \prime}+c^{\prime}$ and that $S=S^{\prime \prime}+s^{\prime}$

If the glass now in physicochemical equilibrium at $T^{\prime}$ is heated with sufficient rapidity to $T^{\prime \prime}$ the resultant expansion and heat absorption will be $C^{\prime}$ and $S^{\prime}$, respectively, while the glass passes through the normal series of conditions, $b b^{\prime}$, which corresponds within this interval to the condition of equilibrium at $T^{\prime}$. If the glass is then held at $T^{\prime \prime}$ until physicochemical equilibrium is established at that temperature by passing along $b^{\prime} a$, a further expansion, $c^{\prime \prime}$, and heat absorption, $s^{\prime \prime}$, will occur. These are only particular values of the expansions and of the heats of absorption required in general by the reactions which may occur at $T^{\prime \prime}$ in producing equilibrium at that temperature, since they are those values associated with the specific change from a condition corresponding at that temperature to the equilibrium at $T^{\prime}$ to equilibrium at $T^{\prime \prime}$.

If the rate of heating is so low, however, that the series, $b a$, of equilibrium conditions is followed, an expansion and heat absorption will be observed which, disregarding signs, will equal the contraction, $C$, and heat emission, $S$, observed during the slow cooling over the same interval. Then since $C=C^{\prime}+c^{\prime \prime}$ and $S=S^{\prime}+s^{\prime \prime}$, it follows that $C^{\prime \prime}-C^{\prime}=c^{\prime \prime}-c^{\prime}$, and $S^{\prime \prime}-S^{\prime}=s^{\prime \prime}-s^{\prime}$.

In the above, therefore, $S^{\prime \prime} /\left(T^{\prime \prime}-T^{\prime}\right)$ and $S^{\prime} /\left(T^{\prime \prime}-T^{\prime}\right)$ are, in general, different although both may be regarded as average true specific heats for the same interval $\left(T^{\prime \prime}-T^{\prime}\right)$. These particular values of the coefficient are to be obtained only by bringing the glass to equilibrium at the starting temperatures before the tests are begun. However, according to the general assumptions made, there must be at any temperature, $T$, a great number of other possible intermediate conditions such as are represented by various positions on $a^{\prime} b$ or $b^{\prime} a$, for example, which a glass might possess whenever a test is started. Corresponding to each of these initial intermediate conditions there is within any temperature interval beginning at $T$ an average true specific heat which differs, in general, from those corresponding to all the others. These values of a thermal coefficient are met whenever a glass follows a series of intermediate conditions like that exemplified by any $d d^{\prime}$ in the interval, $T^{\prime \prime}-T^{\prime}$. (It should be noted that such a series of intermediate conditions yielding a true specific heat may or may not correspond to some condition in the equilibrium series either within or without the section $a b^{\prime}$, that is, the coincidence of two such series which is indicated by an intersection of the representative lines in the accompanying diagram may be only apparent, since one dependent variable with the temperature is inadequate to determine such a coincidence.)

Likewise, the apparent specinic heat, which in the above case is represented by $S /\left(T^{\prime \prime}-T^{\prime}\right)$, will vary depending on the initial condition, which is seldom one of equilibrium and is always conditioned by the mode of heating or cooling. It follows, therefore, that considerable variation may be expected in the results of tests made within intervals including temperatures in, or near, the annealing range. Although the methods of test ordinarily employed are generally favorable, a true specific heat can not, in general, be determined except within temperature intervals well below the softening range. If, however, the end temperatures of these intervals are low enough, the rate of heating, or cooling, has no appreciable effect, and the possibility of differences between true and apparent specific heats in such intervals need not be considered. Furthermore, since length of treatment at these temperatures causes no appreciable change in the condition of the glass, repeated tests on the same piece of glass should always give identical results; that is, the results can not be noticeably changed by varying the treatment preceding the measurements unless the glass was originally very severely chilled or unless the treatments include a heating of the glass to temperatures which rise almost to the annealing range. 
3. All of those processes which may be retarded in glass by chilling and which are the cause of the relatively large exothermic effects observed in heating curves obtained on chilled glasses may be carried forward to such a degree by thorough annealing treatments, and especially by those given at low annealing temperatures, that they will no longer be sufficiently active to produce in the heating curves of annealed glasses any appreciable exothermic effect within the relatively short time allowed by the heating rates usually employed.

4. In annealing at any given temperature to reduce the activity of the exothermic processes during a reheating or a further annealing at lower temperatures, thoroughness is gained by increasing the duration of the treatment; and this activity is usually more completely reduced by treatments at low temperatures, provided the annealing periods can be made sufficiently long.

5 . Since the exothermic processes tend, in general, to proceed much further at low annealing temperatures and since they, at the same time, meet increased resistance to their activity and consequently become much more sluggish, it follows that the annealing periods must be greatly increased as the annealing temperature of a glass is lowered if the thoroughness of annealing which corresponds to approximate equilibria at these low annealing temperatures is to be attained.

6 . As this annealing proceeds the activity of the exothermic processes usually decreases progressively and it may happen that those processes which at first showed the greater activity gradually become less prominent in this respect than others-a result which may be caused either by differences in the rates of advance of the various original processes toward that degree of completion required of each for the establishment of equilibrium at the annealing temperature in question or, possibly also, by the appearance and grow th in importance of secondary processes.

7. Heating a glass rapidly to sufficiently high temperatures either before or after equilibrium has been established at a given treating temperature will replace the activity of the exothermic processes by that of the reversed or endothermic processes.

8. The temperature at which any one of the more important exothermic processes is so reversed will, in general, not be a unique temperature which is characteristic of that process but it will be one which is determined chiefly by the progress which that process has individually made in contributing to the production of an equilibrium at the treating temperature employed before the temperature was increased; and since at any stage of this previous annealing treatment, except that of complete equilibrium, the degrees of progress of the various processes toward establishing such equilibrium may, in general, be considerably different, it follows that the reversal temperatures of the serveral processes may also be correspondingly different.

9. For simplicity consider that there is only one process that is uffected by annealing, and that it is of the type haviug a variable exothermic to endothermic reversal point. Then, so long as the temperature of the glass is below this point, annealing will progress because the process will be exothermically active. As a consequence, the reversal point will be falling, although at a continualiy decreasing rate, until it finally coincides with the olass temperature and stops. Further, if the temperature of the glass is rising, "disannealing" will begin, just as soon as the reversal point is passed, because the reversed 
process will then become endothermically active. In consequence, this point will begin to rise also, but the beginning rate will be relatively slow since it is controlled only indirectly by the rate of heating the glass.

10. This reversal temperature is equivalent to the equilibrium temperature and when once passed it will, on heating, as on cooling the glass, generally lag behind the actual temperature. (See fig: $1(c)$.)

11. That is, if the actual temperature of the glass is still rising after the reversal temperature is passed, superheating will result because of the sluggishness of the endothermic piocess just as undercooling previously resulted because of a similar sluggishness on the part of the corresponaing exothermic process during the cooling; but, as a consequence of the rapidly decreasing sluggishness of the endothermic process as the actual temperature continues to rise, this reversal temperature will soon greatly accelerate its rate of rise and regain much of the lost ground with the result that an abnormal endothermic efiect will ultimately be detectable.

12. If there be only one process, or if the reversal temperatures of the possible several processes are all the same, as they would be in the case of equilibrium, the equilibrim temperature of a specimen of glass may be determined by finding that temperature in the annealing range at which a long heat treatment produces no change in its physical properties; while other similar treatments at temperatures somewhat higher and lower produce changes which, in the density, for example, are ordinarily decreases and increases respectively.

13. In general, it must be assumed, however, that there is, as previously stated, not one but a number of different processes active in a glass during a heat treatment, and that the reversal temperatures of these processes may all be considerably difierent after any period of treatment, such as the usual annealing sehedules which are seldom capable of producing an equilibrium; consequently, it follows that an equilibrium temperature determined as above described does not necessarily coincide with any of these reversal temperatures, although it should always fall at some intermediate position between their extreme values.

14. While this intermediate temperature is therefore not strictly an equilibrium temperature it may be termed the "effective" annealing temperature of the previous heat treatments, since from the method of its determination it is evident that these treatments are capable of producing the same value for the property used in the determination as a thorough annealing treatment would normally have produced at this temperature.

15. Since any given physicai property of a giass is presumably more sensitive to the activities of certain processes than to those of others and since this selectiveness probably changes with the property under consideration, it is to be expected that the effective annealing temperatures determined by observations on different properties will differ somewhat.

16. This possible difference in the reversal temperatures suggests that, in general, glass in proceeding to equilibrium or any other condition passes through a chain of conditions none of which is likely to be that of equilibrium at any temperature, and furthermore, that the number of such possible chains may be very large, although it

$$
43324^{\circ}-31-2
$$


would appear possible by proper treatments of most glasses in their annealing ranges to make reasonably complete transitions from any one of such chains to any other chain.

17. Whenever a glass is subjected to a disannealing treatment at some constant temperature; that is, to a heat treatment at a temperature higher than the effective annealing temperature established by the preceding treatments, the endothermic activity of all the reversed processes decreases at a progressively decreasing rate as this new treatment is continued; and, for much the same reasons mentioned in connection with annealing, the processes initially taking a chief part in this activity may be replaced in this respect by others.

18. As in the case of annealing, the period required for a relatively thorough disannealing decreases rapidly as the treating temperature is raised.

19. In certain cases (usually in the less stable glasses) certain processes somewhat similar to devitrification may appear which have rather definite and unique reversal temperatures regardless of their degrees of advancement.

20 . In other cases, treatments at certain temperatures may advance certain processes to such a degree that other processes which would be very active during treatments in other temperature ranges are partially or completely suppressed, and this suppression may continue unless it is possible to reverse the suppressing processes or otherwise to reduce their effect by some treatment of the glass.

21. Such suppressions make it possible to find, below certain temperatures, sets of chains of conditions about two or more apparently independent equilibrium chains which are more or less parallel and which may be connected only by treatments at relatively high temperatures. (All glasses tend to show similar characteristics below the annealing range while the glasses which exhibit them in this range are exceptions to the class considered under section 16.)

22. The annealing and disannealing under discussion do not take into account the relaxation and introduction of elastic stresses, although these effects may accompany certain of the treatments under consideration.

Because of the above-mentioned changes produced in glass by changing the character of the heat treatment, a comparison of a large number of heating curves obtained on samples that have been prepared by subjecting each of them to one of a properly chosen variety of treatments should show more or less clearly that some of the processes causing the changes are more sluggish than others and that this sluggishness and also the general character of the predominant processes which are active are affected by various conditions, among which are the temperature and the effective annealing temperature of the previous treatments of the samples. Such a comparison should also reval that the reversal temperatures of the several processes active in any one sample are, in general, different except in the case of glasses which are thoroughly annealed at the chosen annealing temperature, and furthermore, that these reversal temperatures, although thoy may depend on the general condition of the glass are determined chiefly by the respective advances which the individual processes had made toward producing equilibrium conditions at low unnealing temprratures during the sample's previous treatments, which naturally include a portion of the heating that was required in obtaining the curves. 


\section{DETAILED EX- POSITION OF THE CURVES}

As already stated above, the purpose of these experiments was to trace the progressive changes produced in the heating curves as the period of treating a glass at a given temperature is gradually increased. These changes are well illustrated by the series of curves shown in Figure 3 . Of these curves, 1 was obtained on a sample broken from a pot of "medium flint" glass, B. S. Melt No. $494 .^{13}$ ' As usual in the case of all glasses taken from pots that are not too quickly cooled, the sample, as the curve shows, was reasonably well annealed. This is evident from the form of the curve because an exothermic effect is lacking and the endothermic effect is quite pronounced. Another sample from the same source was broken into small fragments, and these, after being heated at $620^{\circ}$ C., were chilled from that temperature by being plunged into cold water. ${ }^{14}$ On treating a portion of this chilled sample, curve 2, which shows the form usual for chilled glasses, was obtained. The remainder of the chilled sample was divided into several lots, some of which were heated quickly to $360^{\circ} \mathrm{C} .{ }^{15}$

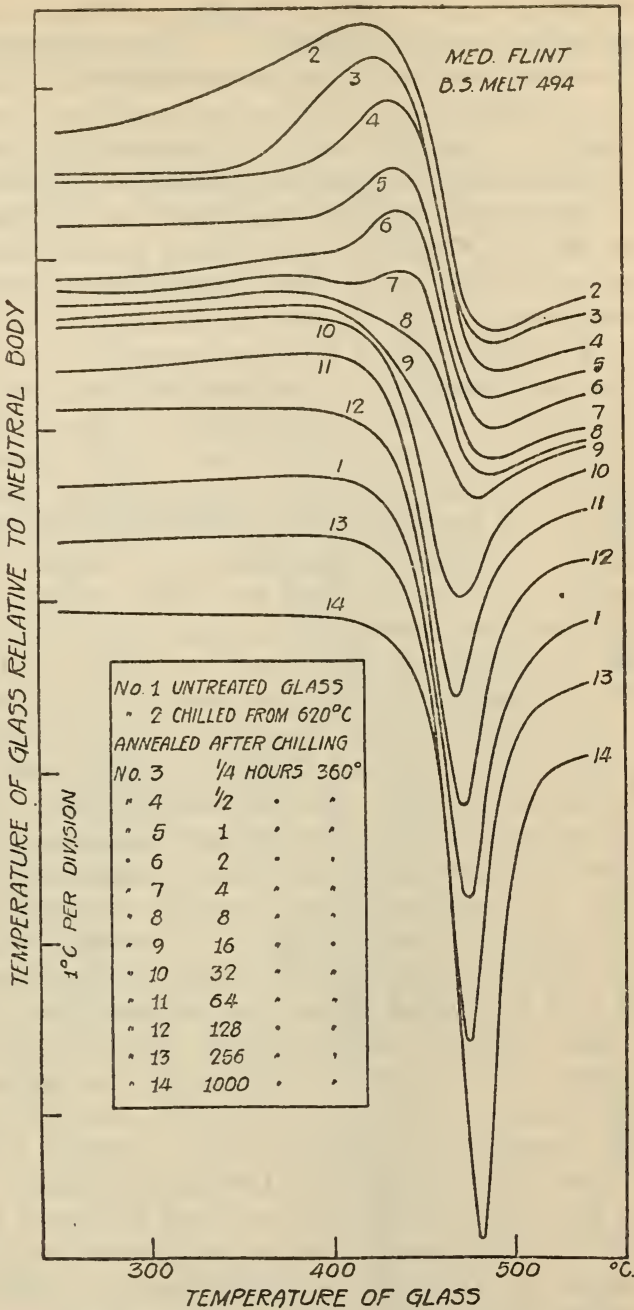

FIGURE 3.-Heating curves obtained on samples of a flint glass where each sample was treated differently as indicated

To make comparison easy the curves have been arranged one above another without reference to zero on the ordinate axis. In practically all cases the width of the lines cover all observed points, and observations were made at intervals of approximately $12^{\circ}, 6^{\circ}, 3^{\circ}$, or $1.5^{\circ} \mathrm{C}$., the shorter intervals bcing employed between $450^{\circ}$ and $550^{\circ} \mathrm{C}$.

${ }^{13} \mathrm{An}$ analysis of this glass gave the following composition: $\mathrm{SiO}_{2}, 50.55 ; \mathrm{Na} 2 \mathrm{O}, 2.69 ; \mathrm{Al}_{2} \mathrm{O}_{3}, 0.65 ; \mathrm{CaO}$, trace; $\mathrm{PbO}, 40.14 ; \mathrm{K}_{2} \mathrm{O}, 5.93 ; \mathrm{Fe}_{2} \mathrm{O}_{3}, 0.02 ; \mathrm{MgO}$, not detected. See also Tool and Hill, Trans. Soc. Glass Tech., 9, p. 196; 1925. This glass and also melts Nos. 431 and 429 were produced under the direction of A. N. Finn at the Bureau of Standards.

is Water was used for quenching, since it is convenient and yields more uniform results than other quenchers, such as liquid air, mercury, etc. When the particles were not too fine the glass could be quickly and easily dried and showed no visible trace of deterioration due to its contact with the water.

${ }_{15}$ The heating temperatures are considered to have been correctly determined to within $\pm 5^{\circ} \mathrm{C}$., and the differences between two such temperatures are probably correct to less than that amount. During the long treatments the temperatures seldom fluctuated more than $5^{\circ} \mathrm{C}$. and then for short intervals only. Naturally, in the 15-minute treatments almost two-thirds of the period was required for the glass to come to the required temperature. 
held there for periods varying from 15 minutes to over 2,000 hours, and then cooled rapidly. This temperature was chosen because it is, for this glass, near the lower limit of the range in which an equilibrium can be established without excecoling a reasonable experimental treating period. Curves 3 to 15 , inclusive (figs. 3 and 4 ) are the results obtained on the samples receiving these treatments.

This series of curves shows that increasing the period of treatment at $360^{\circ} \mathrm{C}$. results in producing a more fully annealed glass, since there is correlated with the increasing period a gradual erasure of the exothermic and a concurrent growth of the endothermic effects. It will also be noted from a comparison of curves 1, 12, and 13 that at this temperature a treatment of more than 150 hours is required ${ }^{16}$ to obtain the curve form found on the original glass. After being subjected to a treatment of about the same period at this temperature relatively large pieces of this chilled glass were found to be reasonably well annealed when examined by one of the usual birefringence tests for strain; consequently, as regards the removal of stresses also, such a treatment does not differ greatly in effect from that received by the glass during the initial cooling in the pot. By such a relatively short treatment (150 hours a.t $360^{\circ} \mathrm{C}$.) the equilibrium condition corresponding to this temperature of the glass was, however, not attained nor would it have been even closely approached unless the treating period had reached 2,000 or 3,000 hours. This conclusion is based both on the fact that the endothermic effect could still be increased materially after a 1,000-hour treatment and that it was later found that treatments of 3,000 hours at least were required at this temperature to secure spproximately constant and stable values for the refractivity ${ }^{17}$ and density. In regard to the growth of the endothermic effect with time of holding at this annealing temperature, $360^{\circ} \mathrm{C}$., it will be noted from the curves that, after the 16-hour treatment which crused the complete disappearance of the exothermic effect (curve 9 ) and until equilibrium was more closely approached through 256 hours' treatment (curve 13), roughly equal increments in the relative cooling of the glass with respect to the neutral body were produced by doubling the treating periods.

Representative curves from Figure 3 are again shown in Figure $\dot{x}$ where, for the purpose of facilitating comparisons, they bave all been made to coincide at approximately $550^{\circ} \mathrm{C}$. which lies in the range where they flatten out on the second level. This point, or temperature, was chosen because the glass under the experimental conditions inrolved in obtaining such curves had not yet begun to sinter so far as could be noticed from a cursory examination and also because it appeared that on reaching this temperature the superheating, together with the resultant endothermic effects, had practically ceased. By discontinuing the heating a little above this point the erratic effects usually accompanying the softeuing of a glass were avoided, while as previnusly stated, it scemed safe to assume that a temperature had 10 Thi does not signify that the pot of glass while being cooled was held for such a length of time in the
Immedisto neighborboor of this temperature because, as a matter of fact, much shorter periods at somewhat likher tomperatures will produce almost the same curve form. Furthermore, a moderate rate of cooling

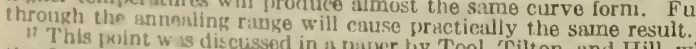

the Optical society of disclissed in a paper by Tool, Tilton, and Hill, which was read at the Ithaca meeting of

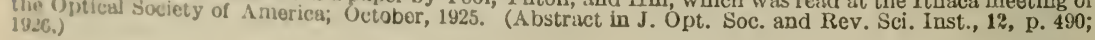


been reached where the physicochemical conditions of all the variously treated samples were practically identical. That is, in this temperam ture range the conditions of the various samples may be considered as being practically independent of all previous heat treatments and as determined almost wholly by the temperatures attained in this final portion of the heating curves. That the effects of all previous heat treatments were eliminated by the required heating to these temperatures and that the conditions of all the samples on reaching the chosen reference temperature employed in these diagrams were practically identical was proved by retesting several of the samples after they were all cooled according to a common schedule from the maximum temperature reached in obtaining the data for this curve series. In every case the retest curves were identical in form; it was found that this form was en. tirely determined by the incidental annealing imposed on the samples by the cooling after the maximum temperature of the first tests was reached.

In obtaining data showing the effect of changing the treating temperature, additional lots of the chilled sample were heated rapidly to $380^{\circ}$ instead of $360^{\circ}$ C.; held there for pe-

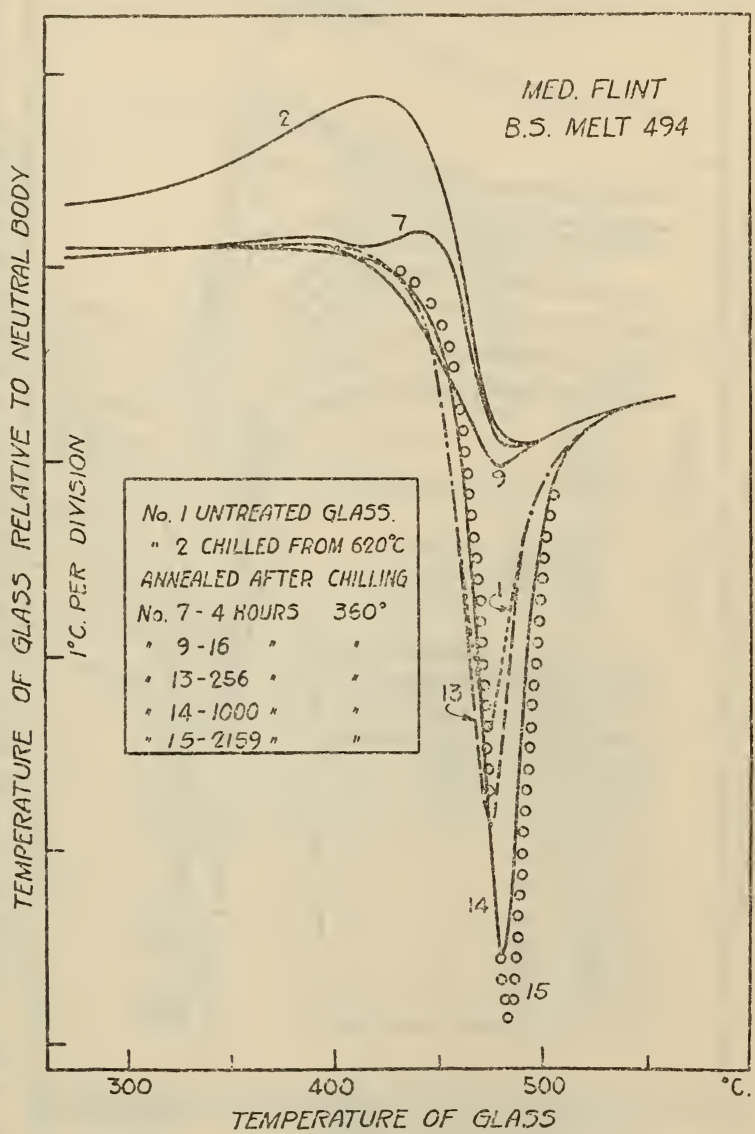

TIGURE 4.-Representative curves chosen from Figure 3 and arranged on the basis of the assumption that all such curves for a given glass should have a common ordinate near the sintering range where it appears that the physicochemical conditions of the respective samples were almost identical riods ranging from 15

minutes to over 1,000 hours, and then cooled very rapidly as before. Together with Nos. 1 and 2 , the hesting curves, Nos. 16 to 24, obtained on these lo ts of glass areshown in Figure 5. This series of curves shows much the same characteristics in the disappearance of the exothermic and in the growth of the endothermic effect as those found in the series of Figure 3. The changes, however, proceeded more rapidly at $380^{\circ}$ than at $360^{\circ} \mathrm{C}$. and less than 100 hours, instead of more than 150 , 
were required at the higher temperature to produce an endothermic effect of the magnitude found in curve 1 . The small increment in the relative cooling of the glass with respect to the neutral body shown by a comparison of curves 23 and 24 in which the holding periods differed by a factor of approximately 9, shows that the glass used to obtain curve 24 had (after the treatment of more than

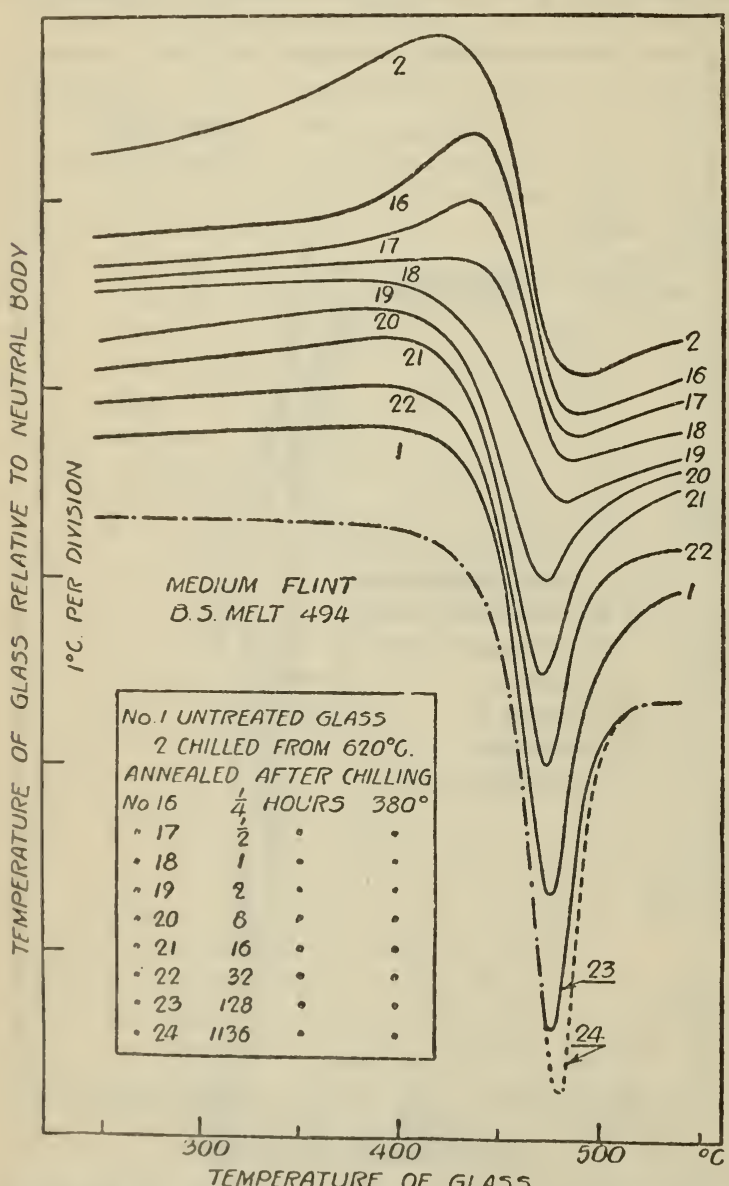

FIGURE 5.-Heating curves obtained on samples of the same fint glass yielding the curves in Figure 3, but with the difference that the special annealing treatments were given at $380^{\circ}$ instead of $360^{\circ} \mathrm{C}$. ing the maximum
at any temperature can also be carried out over other temperature intervals and it demonstrates the reversibility of the processes involved. Experiments at this bureau have shown, however, that other characteristics of glass can be used with much greater facility

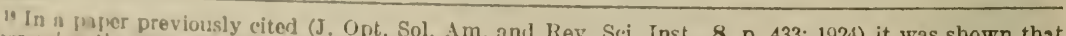
lecreasing the temperature of equilibrium of a glass increased the relative cooling shown by the heating curves, and that all samples of the same glass brought to equilibrium at the same temperature should give
identieal relative coolings. cally reached equilibrium at $380^{\circ} \mathrm{C}$.

That curve 24 corresponds to a practical equilibrium for thisglasswhen treated at $380^{\circ} \mathrm{C}$. is also indicated by comparing it with curve 25 (fig. 6), which was obtained after retreating, for more than 1,000 hours at $380^{\circ} \mathrm{C}$., a part of the lot which was sampled in obtaining curve 15 . The previous treatment had caused this lot of glass to approach equilibrium at $360^{\circ}$ C., and, consequently, the relative cooling indicated by curve 15 is, as should be expected, greater than that shown by curves 24 and 25 , which the comparison shows to be almost identical. ${ }^{18}$ That is, after the treatment at $380^{\circ} \mathrm{C}$., the relative cooling shown by curve 25 is, within the experimental error, the same as that shown by curve 24. This procedure for establish-

1,100 hours) practi- 
in determining accurately ${ }^{19}$ whether a glass has reached equilibrium at any given temperature, consequently this method is not recommended for other than special tests.

In Figures 7, 8, and 9, additional series of similar curves are given which were obtained on a borosilicate crown glass, B. S. Melt No. $431 .^{20}$ The samples furnishing these curves were prepared in the manner described above except that the glass in this case was chilled from $750^{\circ} \mathrm{C}$. and then retreated or annealed at either $450^{\circ}$ or $475^{\circ} \mathrm{C}$., as indicated. Curve 26 was obtained on glass taken directly from the pot, while 27 (see figs. 7 and 8) shows the result on this glass after the chilling. The series in Figure 7 gives another exhibition of the gradual disappearance of the exothermic effect as the period of treatment is increased, while that in Figure 8 again makes apparent the large increase produced in the endothermic effect by lengthening the treating. period. In the case of both series (figs. 7 and 8) the treating temperature was $450^{\circ} \mathrm{C}$. which is near the lower limit of the range where equilibrium can be reached in a practicable time. Here it appears

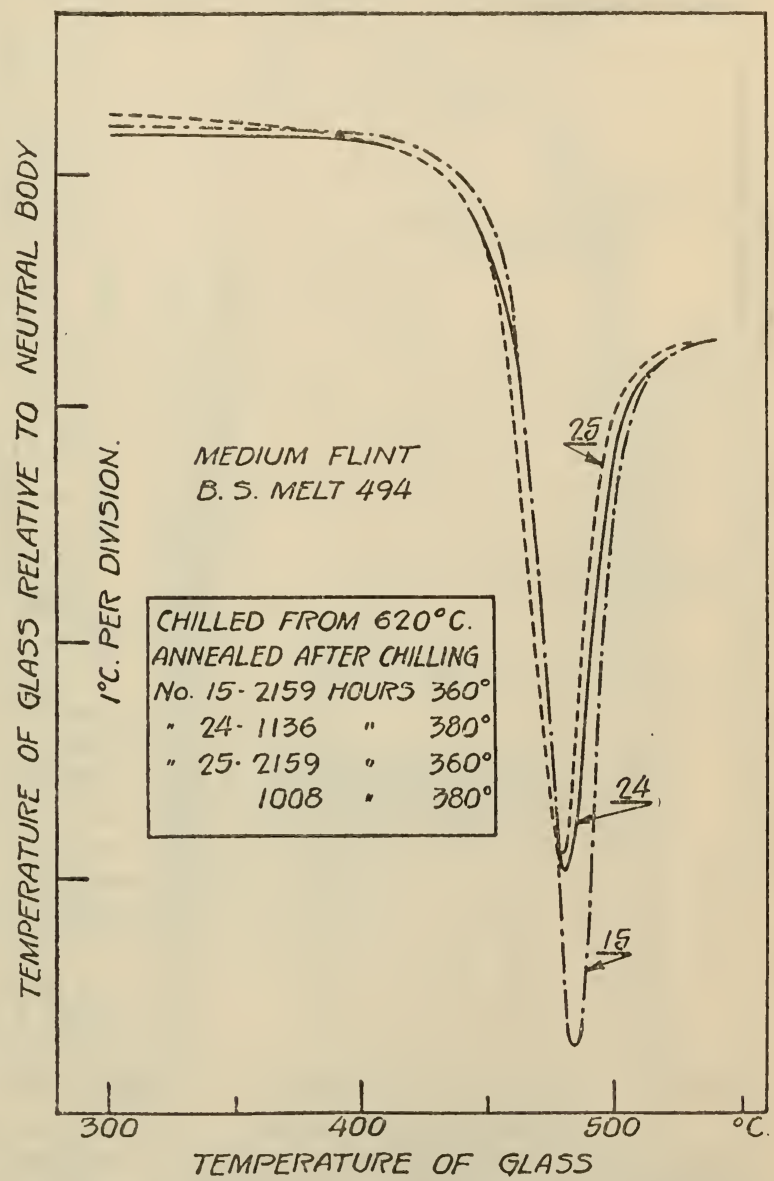

FIGURe 6.-A comparison of the results of approximately thorough annealing treatments received by the chilled flint glass at $360^{\circ}$ and $380^{\circ} \mathrm{C}$.

that approximately 250 hours are required to produce a relative cooling equal to that found on the original glass. (See footnote 16,

10 This was demonstrated on the same glass by curves-shown at the Ithaca meeting of the Optical Society (see footnote 17, p. 540)-giving its change in refractivity with treating temperature. Lebedeff also (die Glas-Ind., 35, p. 6; January, 1927) obtained similar results, but on a difierent glass and in a temperature range where the mobility was much higher. His curves in form and presentation are almost identical with those shown at the meeting mentioned and point to this same advantage of accuracy. See also, A. I. Stozarov, The Variation of Refractive Index of Glasses at High Temperatures, Trans. of the Opt. Inst. in Leningrad, 4 (No. 39), pp. 1-36; 1928. (Since the completion of this paper an article by E. Berger, Glastechn. Ber., 8, p. 339; 1930; has appeared which to some extent discusses Stozarov's results and many of the views expressed in it are in full accord with the general trend of those presented here.)

${ }_{20}$ Analysis of this glass shows the following composition: $\mathrm{SiO}_{2}, 64.52 ; \mathrm{K}_{2} \mathrm{O}, 10.84 ; \mathrm{BaO}_{2}, 2.56 ; \mathrm{R}_{2} \mathrm{O}_{3}, 0.35$; $\mathrm{B}_{2} \mathrm{O}_{3}, 11.93 ; \mathrm{Na}_{2} \mathrm{O}, 7.85 ; \mathrm{ZnO}, 2.66$. See article by Tool and Eichlin, J. Opt. Soc. Am. and Rev. Sci. Inst., 8, p. 421 ; 1924. 
p. 540.) From a comparison of curves 37 and 38 , it will be noted also that a treatment of somewhat more than 4,500 hours seems to have produced a condition of practical equilibrium at this temperature; however, a further slight increase would undoubtedly have been obtained if the period had been very greatly increased.

In obtaining curves 39 and 40 the method discussed above in describing curves 24 and 25 (fig. 6) was used to determine whether

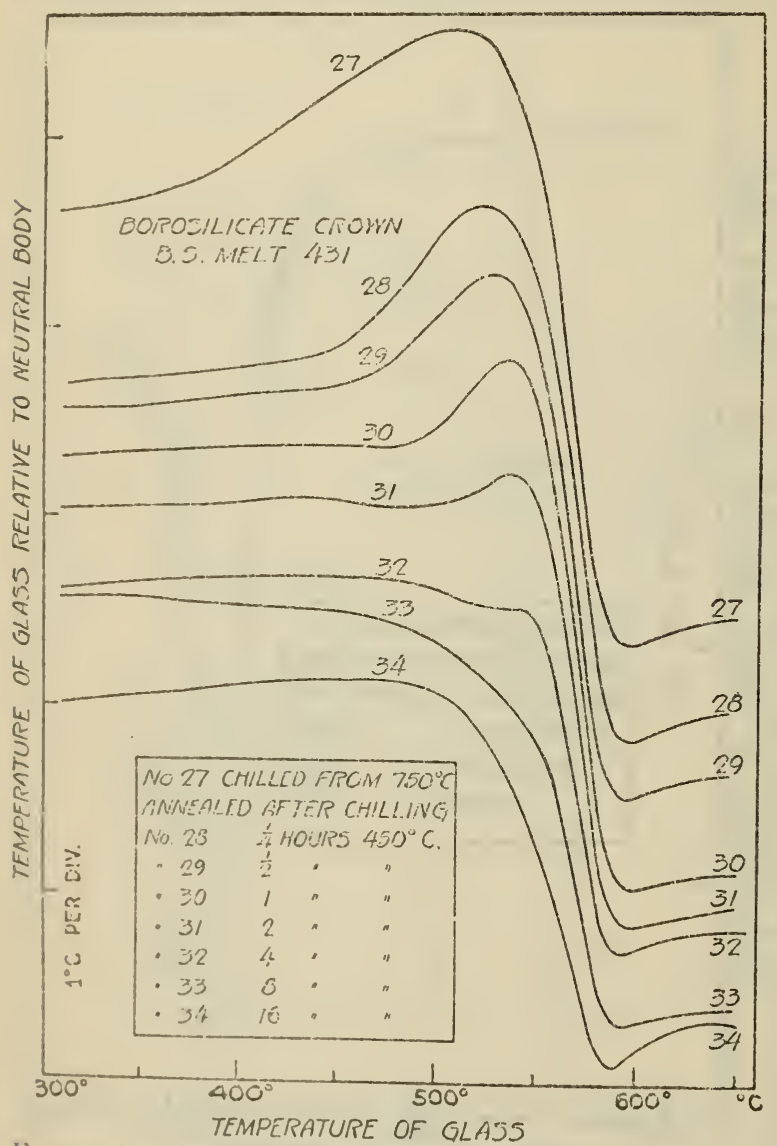

FigUre 7.-Similar heating curves arranged as in Figure 3, but oblained on samples of a borosilicale crown, each rample being differently treated as indicated

In cretention of the low annealing temperature $\left(450^{\circ} \mathrm{C}\right.$.) the annealing

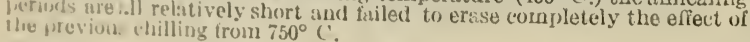
equilibrium $\mathrm{h}$ ad been established in the samples treated at $475^{\circ} \mathrm{C}$. Thus curve 39 was obtained on a second sample taken from the lot that had been treated over 4,500 hours at $450^{\circ} \mathrm{C}$. and had then furnished the sample yielding curve $38 .{ }^{21}$ Before yielding curve 39 this second sample was given an added treatment of more than 1,000 hours at $475^{\circ}$ C. On comparing curve 39 with curve 40 , which was obtained on a sample that was taken from the unannealed chilled glass and then also treated over 1,000 hours o.t $475^{\circ} \mathrm{C}$., it will be seen that the endothermic effects of the two curves are practically the same, although that of the former is somewhat larger, as should be expected. From this it may be inferred, as stated above, that both samples were in practical equilibrium at $475^{\circ} \mathrm{C}$. when the treatments rnded. This inference follows since for one sample the relutive cooling caused by the endothermic effect increased, while for the other it decreased toward a common limit, which it appears was

II In this connection it should he mentioned that the magnitudes of the extreme dips of curves 38 and 39 Frow the fir and secund levels sure not inconsistent with the conclusions drawn from the results given in cunchusions concernet the incrensing lopth of such dips as the equilibrium temperature was decreased. 
practically reached through the 1,000-hour treatments at this temperature.

The series of curves given in Figure 10 and obtained on a light borium crown, B. S. Melt No. $429^{22}$ was discussed in a paper ${ }^{23}$ presented before the Optical Society of Amcrica, but is also included here to show that the manner in which the exothermic effect disappears with an increase in the treating period is much the same for a variety of glasses. Curve 41 resulted from a test on the glass as it came from the pot, while curve 42 was the result on a sample from a lot of the glass which had been chilled from $808^{\circ} \mathrm{C}$. in the manner described above. The other curves were procured on samples from this chilled lot which were treated at $490^{\circ} \mathrm{C}$. for periods indicated in the descriptive legend of the figure. The results obtained after longer periods of treatment are not included, but they were quite similar to those shown for the other glasses.

Those curves in Figures $3,5,7$, and 10 that were obtained on glasses which were in the intermediate conditions that must be passed through as the activity of the various processes and reactions advances a glass toward equilibrium and before the last trace of the exothermic effect disappears, all show certain peculiar transitional changes in curve form which corresponds to certain differences in such intermediate conditions. Thus, on considering the region below the treating

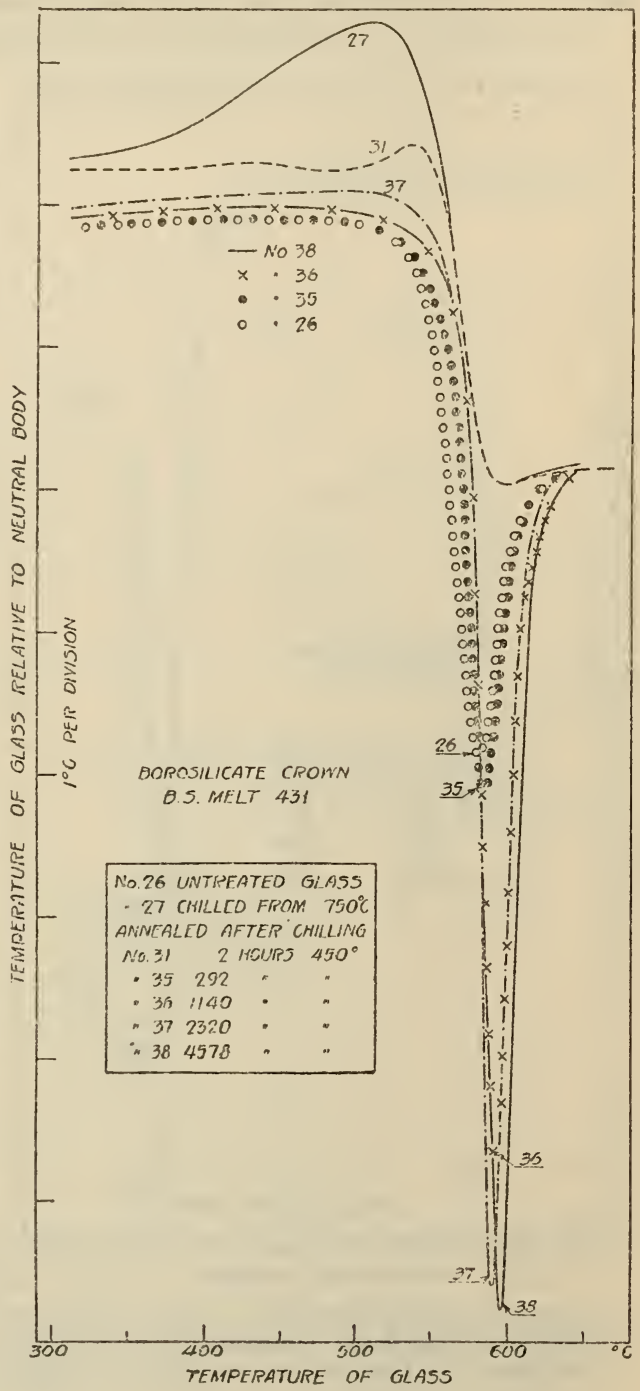

Figure 8.--Selecied heating curves for the same borosilicate crown showing the effectiveness of much longer annealing periods at $450^{\circ} \mathrm{C}$. in removing the efject of chilling from $150^{\circ} \mathrm{C}$.

temperatures, it is seen that a 15 -minute treatment reduced the first level of the curves to its normal height for an annealed glass and

${ }_{22}$ The composition of Melt $\mathrm{No}$. 429 is approxinutely: $\mathrm{SiO}_{2}, 47.8 ; \mathrm{BaO}, 27.1 ; \mathrm{MgO}, 0.2 ; \mathrm{K}_{2} \mathrm{O}, 7.6 ; \mathrm{B}_{2} \mathrm{O}_{3}, 4.3$; $\mathrm{CaO}, 2.5 ; \mathrm{ZnO}, 8.2 ; \mathrm{Na2} \mathrm{O}_{2.1} ; \mathrm{l}_{2} \mathrm{O}_{3}, 0.2$.

${ }_{23}$ Some Thermal Elfects $)$ iserved in (Chilled (dliss, Towl and Eichlin, Rochester, N. Y'.; Oct. 22-26, 1921. 
thereby eliminated in this temperature range practically all trace of an exothermic effect, although it produced only a relatively small reduction in that effect at higher temperatures. As the length of treatment increased, the exothermic effect at these higher temperatures was gradually reduced, although a vestige of it may often be detected in curves obtained on samples which

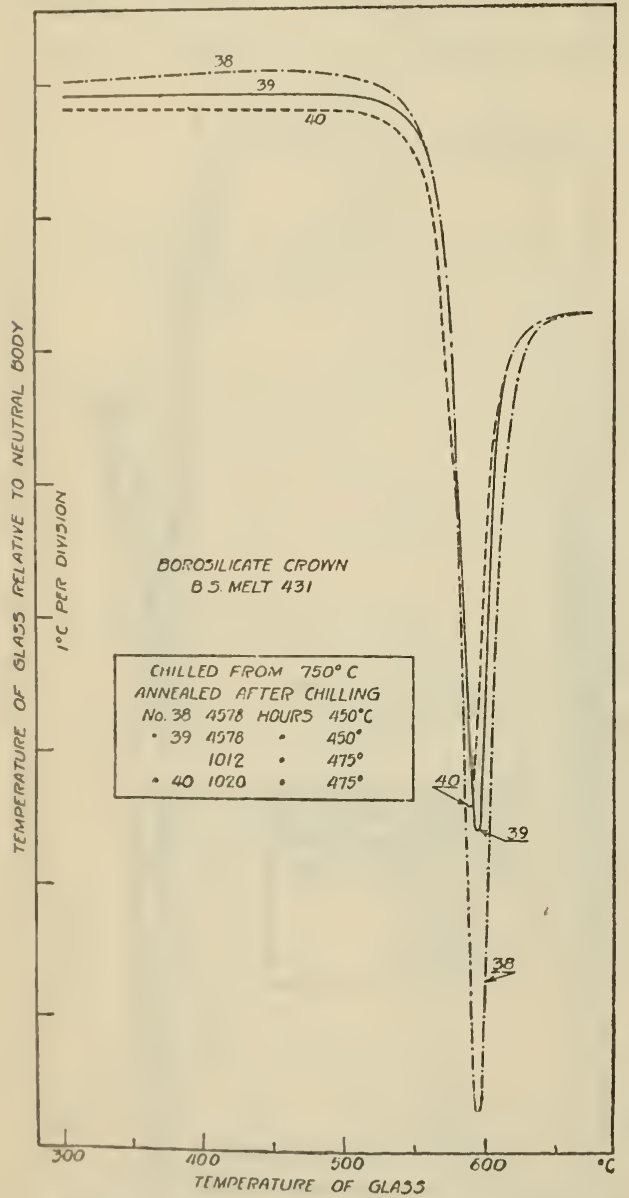

FigURF 9.-A comparison of the results of relatively thorough annealing treatments received by the chilled borosilicate crown at $450^{\circ}$ and $4 \pi 5^{\circ} C$.

previous treatment may easily be more act have received a treatment for many hours. Whenever tests of this nature are carried out it will be found that in almost every case some of the moderately short treatments, especially if they are given at low temperatures, result in curves having the form shown by curve $\boldsymbol{y}$ (fig. 3), where a slight but characteristic depression occurs in the curve in the temperature range corresponding to the beginning of the normal endothermic effect of a glass that is well annealed. This probably signifies that certain exothermic processes were practically completed by these moderately short treatments to the extent required for equilibrium at the low annealing temperature, but that they were reversed as soon as the glass was heated to higher temperatures and became endothermically active before the reversal temperatures of certain other more sluggish, but still exothermically potent processes had been reached. ${ }^{24}$

A study of these curves also suggests that at times an exothermic process whose reversal temperature is found to be near that of the whose after the same previous treatment is

"I certain amount of evidence has been found showing that some of these exothermic processes in inmmplotely nnnealed glasses to not reach their maximum activity until tcmperatures near the upper limit of the usual endothermic ellect are reached. In the case of the borosilicate investigated this would be in the nelshborhond of $600^{\circ} \mathrm{C}$. Such ovidence is, however, diflicult to obtain, since all exothermic effects in this rango are masked by tho greuter endothermic eflocts arising from processes baving lower reversal tem- 
much higher, but whose activity might have been the greater and more potent of the two if the preceding treating temperature had been higher. Whenever there is any marked interference between such processes this change in relative activity with temperature makes it possible through a proper manipulation of treatments and cooling rates to aid either process in suppressing or hindering the other.

Some results on two other types of glass are presented in Figure 11. Of the fused germanium dioxide prepared in the laboratories of Cornell University only a limited sample was available for test. Expansivity measurements made on this glass by C. E. Merritt, of this bureau, indicated that it was unannealed, yet it will be noted that the exothermic effect shown by curve 48 for the untreated glass is small. Likewise the endothermic effect in curve 49 obtained after annealing the glass was not large, although it might have been increased possibly by choosing a more favorable heat treatment. As usual the annealing treatment did not change the difference between the first and second levels greatly.

This difference is, however, smaller than that ordinarily observed with

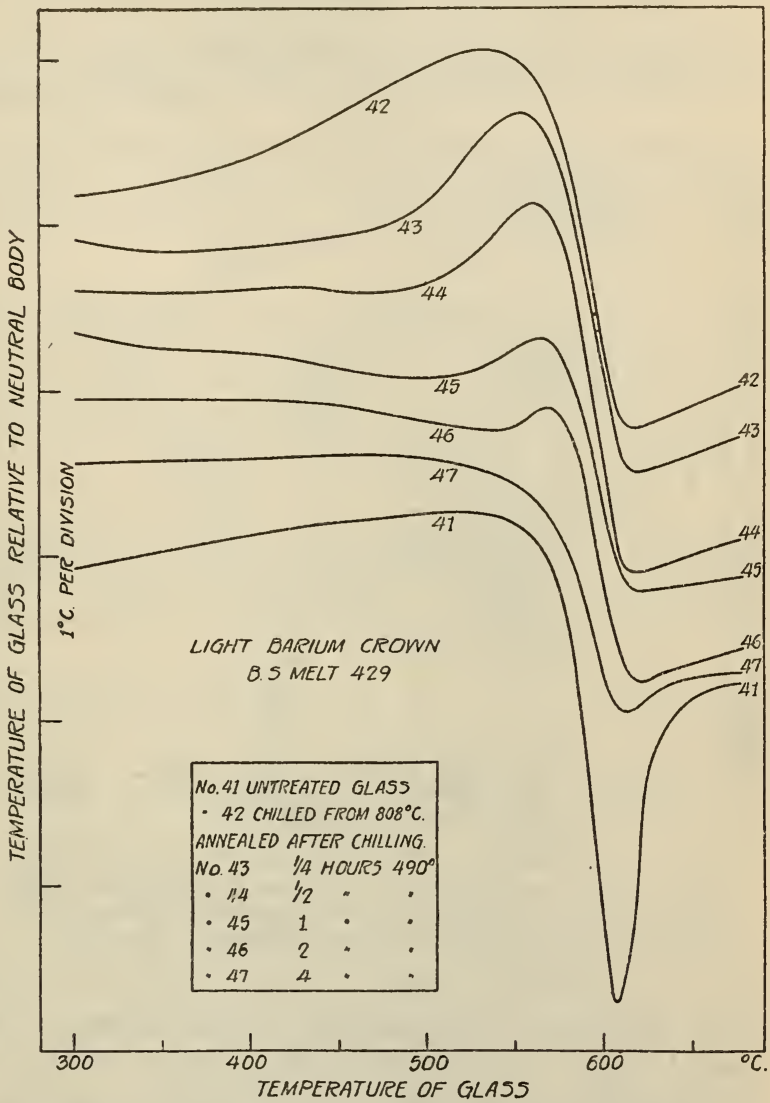

FIGURE 10.-Heating curves obtained on samples (differently treated as indicated) of a barium crown

These curves show that the forms of the curves presented in Figures 3, 5 , and 7 and obtained after short periods of annealing chilled samples are typical results for chilled glasses that have been insufficiently annealed at low annealing temperatures. other glasses tested.

The relative smallness of the exothermic and endothermic effects before and after annealing, respectively, and of this difference between levels as compared with the corresponding effects in most other glasses may possibly be ascribable both to a smaller tendency toward intramolecular changes in this glass and to a greater sluggishness on the part of its processes.

The silicate of soda glass was a soluble commercial product of undetermined composition. Curve 50 was taken on some of the original 
or untreated glass, while curve 51 is the result obtained on a sample after it had been treated over 600 hours at $380^{\circ} \mathrm{C}$. It is evident from these curves that this treatment greatly increased the endothermic effect. In fact, so far as has been observed, this effect is always increased when any iniperfectly annealed glass is reannealed in the range immediately below the temperature where the effect normally begins.

\section{GENERAL DISCUSSION AND CONCLUSIONS}

1. From the data and discussions presented it is evident that the conclusions reached in the previous papers cited concerning the possi-

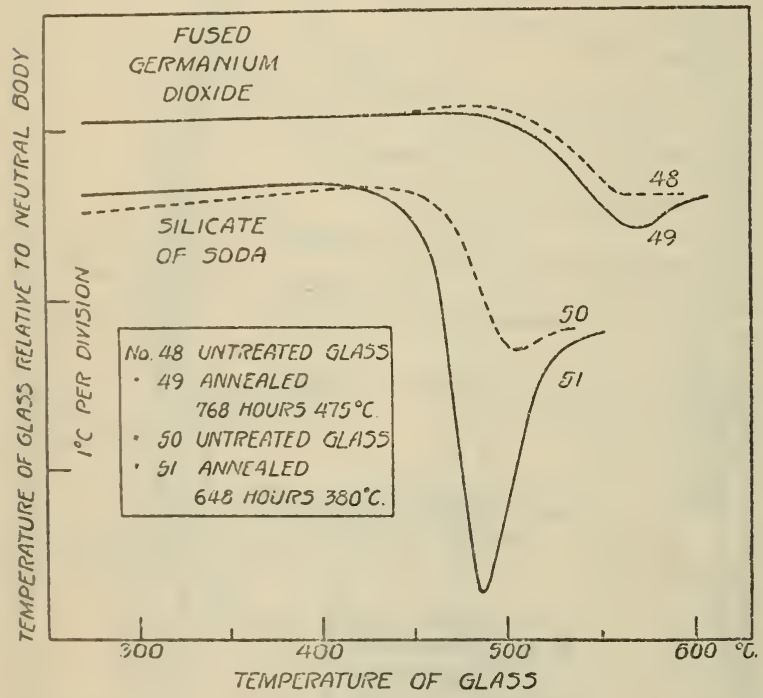

IIUURE 11.-Heaing curves of two glasses, one of which is rare and was produced for experimental purposes only, while the other, although produced commercially, is naiurally not employed for the usual purposes of a glass bility of establishing equilibrium conditions in glass are well supported.

2. With a given glass these conditions vary with the temperature and form a continuous chain of equilibrium conditions which generally extends throughout the practical annealing range and often to both higher and lower temperatures.

3 . When a glass is treated at a chosen temperature the equilbrium for that temperature is approached at a constantly decreasing rate as the treatment is continued; that is, the reaction rates of the efiective proc-
esses decreases exponentially as the treating time increases and the initial rate is correspondingly greater when the initial condition is farther removed from the equilibrium condition approached.

4. These reaction rates may also depend somewhat on the direction from which equilibrium is approached; that is, the initial rate of approaching equilibrium may depend on whether the difierence between the cffective annealing temperature of the initial condition nud the treating temperature is positive or negative although the absolute magnitude's of these differences as measured by the changes in some characteristics of the glass may be equal.

5. Moreover, in the temperature ranges covered by these inves. tigations and also by those on refractivity and density, both the velocity of these reactions, when the initial conditions, so far as can he determined, are about equally removed from equilbria, and the Inobility of the glass appear to vary with the treating temperature in a manner which follows more or less closely the empirical rule 
which has been derived from such compilations of data as that of van't Hoff 25 on the change of reaction velocity with temperature.

6. In gencral, both the stable condition tow ard which a glass of given composition ${ }^{26}$ is advancing during treatment and the velocity of this reaction should be determined, mot only by the treating temperature but also by the previous themmal history. So long, however, as this history is limited to treatments that are confined to the annealing range or still lower temperatures, most of the glasses so far tested do not show any marked effects of the previous history ${ }^{27}$ which interfere with an almost perfect reversibility at all temperatures within the annealing range.

7. Some glasses, for example, some of the pyrex group, ${ }^{28}$ are exceptional in this respect, since treatments in certain parts of the annealing range seem to induce conditions in these glasses which lead to different equilibrium chains or sequences at lower temperatures in that range.

8. These conditions developed in the annealing range are apparently induced by the excessive advancement of certain processes which causes an almost complete suppression of other processes which would lead to a different equilibrium sequence which may or inay not be nearer that secuence followed when the cooling is extremely slow.

9. Reversing the suppressing processes by heating the glass to higher temperatures which are near or somowhat above the annealing range usually restores it again to conditions which are in the slow cooling sequence and are also common to the other equilibrium sequences involved.

10. While the glass may in many cases be carried through an indefinite number of cycles about each of these sequences there is at times some indication of a very slight drift from some of these possible sequences toward certain others which it would appear are usually those nearer the slow cooling sequence. This would seem to

${ }^{25}$ van't Hoff, Chemische Dynamik, p. 225; 1598. Ref. from Nernst's Theoretical Chem. van't Hoff, Chemical Dyanamics, p. 125; 1896. Translation by Ewan.

25 In this connection the effect oi ever-present impurities, dissolved gases, etc., can not be entireiy neglected, but as so little is krown, in general, concerning their action, an attempt at this time to analyzo any possible relation they may have to the heat effects and the various changes caused by different heat treatments appears to be uscless.

${ }_{27} \mathrm{It}$ is evident from the foregoing discussion that any glass in common use can not be reduced to equilibria corresponding to ordinairy or atmospheric conditions; and even at relatively high temperatures there is, with some glasses at least, a question concerning whether the condition actually developed is the ultimate condition of stability that rould have been reached if the resistance met at various periods during the cooling from the molten state had not grown too great to allow a suficientiy rapid readjustment. This guestion remains even though a certain reversibility is later ohtained when the temperature of treatment is raised and lowered reneaterly through various cycles in the annealing range. If the failure to reach a condition of ultimate stability can result from thic previous heat history at relaitively high temperatures as weil as the temperatures in the annealing range, it may well happen in some cases that varying the number, length, and type of treatments in certain ranges (the molding range, for example) may bring such a condition considerably nearer and materially change the apparent equilibrium series of conditions at other, and especially at lower temperatures.

This effect of prerious history at high temperatures leads to the possibility of morc than one equilibrium series throughout the anncaling range of a gless as well as in the still lowe: ranges previously mentioned. In part, this cossibility is the basis for the feeling sometimes expressed that changes in the method of processing glass at high temperatures produce permanent difierences in its proporties without altering the compsoition; and it is a very good reason for experiments, such as those of Eckert (Zeit. f. Tech. Phys., p. 282; 1924). It has been found, howerer, that, as his resulis also indicate, irreversible effects of previous history at molding temperatures are probably :moll, sinca preheating most glasses to relatively high tenperatures before reannealing will csually erase such differences in properties as may have been observed in a glass at lower temperatures unless the causes of such differences were originally produced at temperatures well above the annealing range (for example, by long treatments in the molding range or at even higher temperatures). In such cases the causes may have constituted a change in composition, something having the nature of a devitrification, or rossibly a grecter degree of segregation of the components as their Inutual solubility decreised at temperatures below the melting range. Increasing devitrification caused by prolonged treatrients at high ternneratures irill, for example, cause a grnúlual shift of the range in which the endothermic effert olserved in heating curves is obtinined.

${ }_{28}$ Tool and Hill, Trans. Soc. Glass Tech., p. 8, 196; 1925. Tool, Pefier, and Saunders, T'oronto Meeting American Ceramic Soc., Toronto, Canada; Februai'y, 1930. 
indicate that there is often a varying degree of approximate stability in these sequences and that the suppression of those processes whose lack of advancement caused the glass to enter tho less stable sequence was not complete.

11. It may well be that the chief difference between glasses showing this effect and the apparently more common type which do not is chiefly a matter of the detectability of the effect and of the temperature range in which it occurs. That is, all glasses at temperatures below the annealing range may be made to follow a large number of different sequences about which it is possible to carry them through apparently closed cycles of conditions; but it may well be that these sequences constitute a series of only quasistable conditions, and that if the cycles about them are repeated a sufficiently large number of times a drift could be detected toward the sequence of equilibrium conditions which apparently can only be reached by a cooling treatment that would be so extremely slow that it would be impractical, if not impossible. ${ }^{29}$

12. The two glasses (B. S. Melts, Nos. 431 and 494) which yielded the greater part of the data given in this article and which with a number of others have been thoroughly investigated with regard to the refractivity and density changes ${ }^{30}$ which are possible as a result of treatments in the annealing range, ${ }^{31}$ each gave evidence of only a single equilibrium sequence in this range although at lower tempera-

${ }^{20}$ In annealing ordinary glassware it is not economically feasible to establish a fully stable condition at any point in the annealing range excopt possibly at the highest temperatures and from these, cooling can not be accomplished rapidly without the introduction of strain unless the articles are small. Since economy roquires tho shortest an 2ealing procedure possible, the chief object, so far as the physicochemical condition is concerned, must be the obtaining of a reasonable uniformity in this condition throughout the piece of ware and the maintaining of this uniformity until comparatively low temperatures are reached where thero is no danger that it will be disturbed materially. If the glass be heated to temperatures just below those where undesired deformations are to be foared, such a uniformity of condition within the glass is usially established very quickly if the temperature distribution in the ware is uniform. Furthermore, this uniformity of condition will generally be maintained to a suficient degree throughout any cooling procodure that does not introduce undesirable strain. The physicochemical condition resulting from such a treatmont will usually corrospond, at least roughly, though not exactly, to one of equilibrium at some temporature which can bo determined approximately. (See par. 14, Pt. IV.) If this temperature is fairly low in the annealing range, the changes in the condition of the glass will neither be noticeable over reasonably long periors nor markedly different in the various parts of the piece so long as it is always used at considerably lower temperatures and is not subjocted to large and long-continued temperature differences bet ween its parts.

'This ordinary annealing is, however, not adequate for glass intended for precision apparatus even when there is no strain of an undesirable magnitude present. For example, it was shown in the paper cited in footnote 17 that a gradient of $1^{\circ}$ per meter within the annealing furnace, while it is being leld at the annealing tempernture might easily cause such a lack of physicochemical homogeneity that variations of soveral units in the sixth decimal of the refractivity would result even within pieces of glass whose major dimension was not more than $10 \mathrm{~cm}$.

${ }_{30}$ Tool and Hill, Trans. Soc. Glass Tech., 9, p. 196: 1925. Annual Reports of the Director of the Bureau of Standards, U. S. Department of Commerce, pp. 11, 23, 21, and 25 of years 1925, 1927, 1928, and 1929,
respectively.

3 Sinco gliss is employed chiefly at ordinary temperatures, data which are obtained on its refractivity and density under such conditions and which are serviceable in deternining the effective annealing temperatures aro more important from a practical standpoint than those obtained on tho same properties at temperstures where the glass is being treated for the establishment of equilibrium conditions. Theoretically, howevor, it is also very important that data on these properties should be determined not only at a standard temperature in the range where glass is ordinarily used, but also at several temperatures in the range where ecpuilibria can be attained. In fact, this should bo done in every range where appreciable changes of any sort from heat treatmont are likely. Only in this way can the relations between the properties of glnss at differont tomperatures and in different conditions of equilibrium be satisfactorily determined, and the olfocts of annoaling, of cooling at different rates, and of other variations in the treatments be fully oviluated.

Early in the progress of theso investigations consideration was given to an intarference method whereby the rate of approaching equilibrimin could bo studied and whereby other tests regarding this condition could be made through data simultancously obtained on both the density and the refractivity changes whlch occur whilo the annoaling, cooling, and hoating treatments are being accomplished. So far, however, very littlo progress has beon made on this project; and since such a method becomes tedious when the changes yrogross as slowly as they do at tho lower temperatures of the annealing range which, from the standpoint of optical glisses, aro the most important it was decided to use for that range of treating temjerstures the lass comprohensive mothod described in a previously mentioned paper. (Seo footnote 17, P. 510 .) That the interferonce mothod could be used to advantage in the upper annealing range is shown by I seberleft's (fuotnote 19 p. 543) data (obtained by another mothod) on the rofractivity changes occurring
during trostment. 
tures there was the usual multiplicity of such sequences, ${ }^{32}$ about which cyclic chains of "intermediate" 33 conditions may be established by suitable heat treatments at different points in a series of temperature cycles.

13. This tendency of glass to follow sequences of quasistability at relatively low temperatures is presumably due to the persistence of certain reversible processes after many of the important ones in the annealing ranges have been suppressed. Among the important processes which persist are those responsible for the true expansivities and contractivities as well as those which produce the modifications which result in the corresponding apparent coefficients.

14. Without taking into account the possible effects of the previous history of a glass at temperatures above the annealing range and considering only the great number of unstable sequences which it may be made to follow in the annealing range and which apparently become equilibrium series of conditions at still lower temperatures where they may be made to branch into a still greater number of such sequences because of certain unsuppressed processes, it will be seen that the apparently stable conditions in which a glass may be procured at room temperatures is unlimited and that any of its properties can be made to assume values anywhere within ranges of considerable breadth.

15. The density and refractivity, for example, can be varied in the neighborhood of 1 per cent, and roughly one-half of this may be procured by varying the treatments in the lower part of the annealing range which is that portion of the range utilizable for optical glass.

16. The various effects mentioned are also found in simple glasses; that is, those comprising only one oxide, ${ }^{34}$ such as $\mathrm{B}_{2} \mathrm{O}_{3},{ }^{35} \mathrm{SiO}_{2}$, or $\mathrm{GeO}_{2}$, as well as in the more complex. ${ }^{36}$

32 Tool, Lloyd, and Merritt, B. S. Jour. Research, 5, p. 627; 1930 . J. Am. Ceramic Soc., 13 , p. $632 ; 1930$.

33 The term "intermediate condition" refers to one which arises, for example, during the transition from a condition of equilibrium at one temperature to that at another, but which may not be one of equilibrium at any temperature. (Se; footnote $12, \mathrm{p} .534$.$) The possibility that such conditions are produced in glass$ has been mentioned prøviously (see article by Tool and Hill, J. Sэc. Glass Tech., 9, 190; 1925), and it should be added that analogous conditions may arise even in very fluid solutions when the temperature is varied rapidly.

34 It is possible that there may be several components in a glass with only one constituent oxide and that the equilibrium between these possible components may vary with the temperature. The processes involved in producing such an equilibrium condition might account for the thermal effects noted in the simple glasses mentioned as wall as in the more complex. To some, these different components may appear to be caused by varying degrees of polymerization and the formation of complex molecules from groups of simple units as predicated by different theories. (For example, see theory of Asch and Asch, The Silicates in Chemistry and Commerce, Translation by Searle, Constable \& Co., London; 1913.) Others may see a similarity between these effects in glass and the development of the more orderly molecular arrangements which have apparently been detected by means of X-ray studies of different liquids as they approach their congealing temperatures. It may also seem that the processes contemplated in both views may either be independent or related in their possible responsibility for the changes observed in glass, but in view of the data available at present it would appear inadvisable to speculate too doeply concerning the nature of the processes involved in the various unknown molecular rearrangements which probably occur.

${ }_{35}$ In view of the probable density changes coincident with changes in rate of cooling a $\mathrm{B}_{2} \mathrm{O}_{3}$ glass (in regard to the heat absorption effect in this glass see Tool and Valasek, B. S. Sci. Papers, No. 358; 1920) it would appear unsafe to base conclusions concerning the relative atomic weights of boron in different samples on density measurements made on this glass, as Briscoe, Robinson, and Stephenson (J. Chem. Soc., London, p. 70 , pt. 1 ; 1926) appear to have done, unless great care is taken to cool the whole set of samples required in any one comparative test according to the same schedule.

36 It would appear that similar effects should be found in glasses containing no silica or, for that matter, any of the other necessary acidic constituents common to ordinary commercial inorganic glasses. This leads to the assumption that they are probably present in all vitreous organic materials as well. Such a view is supported by the results of M. O. Samsoen, Contribution a L'étude de L'état Vitreux et de la Dilatation des Verres (1927) and also of G. S. Parks and various collaborators:

Gibson, Parks, and Latimer, J. Am. Chem. Soc., 42, p. 1547; 1920.

Gibson and Giangue, J. Am. Chem. Soc., 45, p. 93; 1923.

Parks, and Latimer, J. Am. Chem. Soc. 4\%, 341; 1925.

Parks and Huffman, Sci., 64, p. $364 ; 1926$.

Parks and Huffman, J. Phys. Chem., 31, p. 1842; 1927.

Parks, Huffman, and Cattoir, J. Phys. Chem., 32, 1368; 1928.

Cattoir and Parks, J. Phys. Chem., 33, p. 879; 1929.

Parks and Gilkey, J. Phys. Chem., 33, D. 1428; 1929.

In these articles many other important references are noted which bear directly on the nature of the vitreous state. 
17. This degree of possible variation emphasizes the need for great care in duplicating exactly the anncaling conditions whenever it is necessary to produce a high degree of uniformity ${ }^{37}$ in any property of a large piece or a large number of pieces of a glass.

18. It also suggests the use of variations in the annealing schedule for the purpose of compensating for small differences in certain properties where such differences result because of slight accidental variations between the compositions of different melts.

19. Furthermore, it shows the caution which must be exercised whenever it is desired to determine the effect a change in certain constituents of a glass will have on any property, such as density or refractivity. This follows since any change in composition also changes the annealing characteristics of a glass and usually makes it inadvisable to follow the same annealing schedule for all samples while at the same time there are no adequate clues as to what would be the equivalent schedules in the various cases.

Washington, Scptember 1, 1930.

37 Tilton, Finn, and Tool, B. S. Sci. Papers, 22 (No. 570), p. 719; 1928. Tilton, Finn, end Tool, J. An. Coramic Soc., 11, 292; 1928. 